\title{
The Reward Circuit: Linking Primate Anatomy and Human Imaging
}

\author{
Suzanne N Haber ${ }^{\star, 1}$ and Brian Knutson ${ }^{2}$ \\ ${ }^{1}$ Department of Pharmacology and Physiology, University of Rochester School of Medicine, Rochester, NY, USA; \\ ${ }^{2}$ Department of Psychology, Stanford University, Stanford, CA, USA
}

Although cells in many brain regions respond to reward, the cortical-basal ganglia circuit is at the heart of the reward system. The key structures in this network are the anterior cingulate cortex, the orbital prefrontal cortex, the ventral striatum, the ventral pallidum, and the midbrain dopamine neurons. In addition, other structures, including the dorsal prefrontal cortex, amygdala, hippocampus, thalamus, and lateral habenular nucleus, and specific brainstem structures such as the pedunculopontine nucleus, and the raphe nucleus, are key components in regulating the reward circuit. Connectivity between these areas forms a complex neural network that mediates different aspects of reward processing. Advances in neuroimaging techniques allow better spatial and temporal resolution. These studies now demonstrate that human functional and structural imaging results map increasingly close to primate anatomy.

Neuropsychopharmacology Reviews (2010) 35, 4-26; doi: I 0. I038/npp.2009. 129; published online 7 October 2009

Keywords: orbital prefrontal cortex; probability; reward anticipation; reward magnitude; substantia nigra; ventral medial prefrontal cortex; ventral striatum

\section{INTRODUCTION}

The demonstration by Olds and Milner that rats would work for electrical stimulation in specific brain sites led to the idea that there is an anatomically identifiable reward circuit (Olds and Milner, 1954). Support for the existence of such a circuit came with pharmacological manipulation of those sites, in particular intracranial injections of drugs of abuse (Carlezon and Wise, 1996; Carr and White, 1983; Phillips and Fibiger, 1978). Although several brain regions are part of this circuit, based on self-stimulation, pharmacological, physiological, and behavioral studies, the nucleus accumbens (NAcc) and the ventral tegmental area (VTA) dopamine neurons appear to be at the center (Hikosaka et al, 2008; Kelley and Berridge, 2002; Rolls, 2000; Schultz, 2000; Schultz et al, 2000; Stefani and Moghaddam, 2006; Wise, 2002). Recent studies have shown that the striatal and midbrain areas that are involved in the reward are more extensive than previously thought. They include the entire ventral striatum (VS) and the dopamine neurons of the substantia nigra (SN), respectively. The VS receives its main cortical input from the orbital

${ }^{*}$ Correspondence: Dr SN Haber, Department of Pharmacology and Physiology, University of Rochester School of Medicine, 601 Elmwood Avenue, Room 5-7425, Rochester, NY 14642, USA, Tel: + 15852754538 , Fax: + 1585273 2652, E-mail: suzanne_haber@urmc.rochester.edu Received 16 May 2009; revised 1 August 2009; accepted 4 August 2009 frontal cortex (OFC) and anterior cingulate cortex (ACC) and a massive dopaminergic input from the midbrain. The VS projects to the ventral pallidum (VP) and to the $\mathrm{VTA} / \mathrm{SN}$, which, in turn, project back to the prefrontal cortex, via the medial dorsal (MD) nucleus of the thalamus. This circuit is an integral part of the cortico-basal ganglia system. In addition, other structures including the amygdala, hippocampus, lateral habenular (LHb) nucleus, and specific brainstem structures, such as the pedunculopontine nucleus and the raphe nuclei, are key components that regulate the reward circuit (Figure 1).

Reward is a central component for driving incentivebased learning, appropriate responses to stimuli, and the development of goal-directed behaviors. One of the main goals of animal and human studies is to understand how the different brain regions in the circuit work together to evaluate environmental stimuli and transform that information into actions. A key challenge is to translate what we know about reward from animal studies to the human brain. At the foundation of brain image analysis is anatomy, the identification of structures and their connectivities. While the basic anatomy of the structures and pathways of the reward circuit are now well established, new anatomical studies continue to add important data that shape our understanding of how its different components are related. In contrast to animal studies, human imaging work is relatively new. Nonetheless, there has been an 


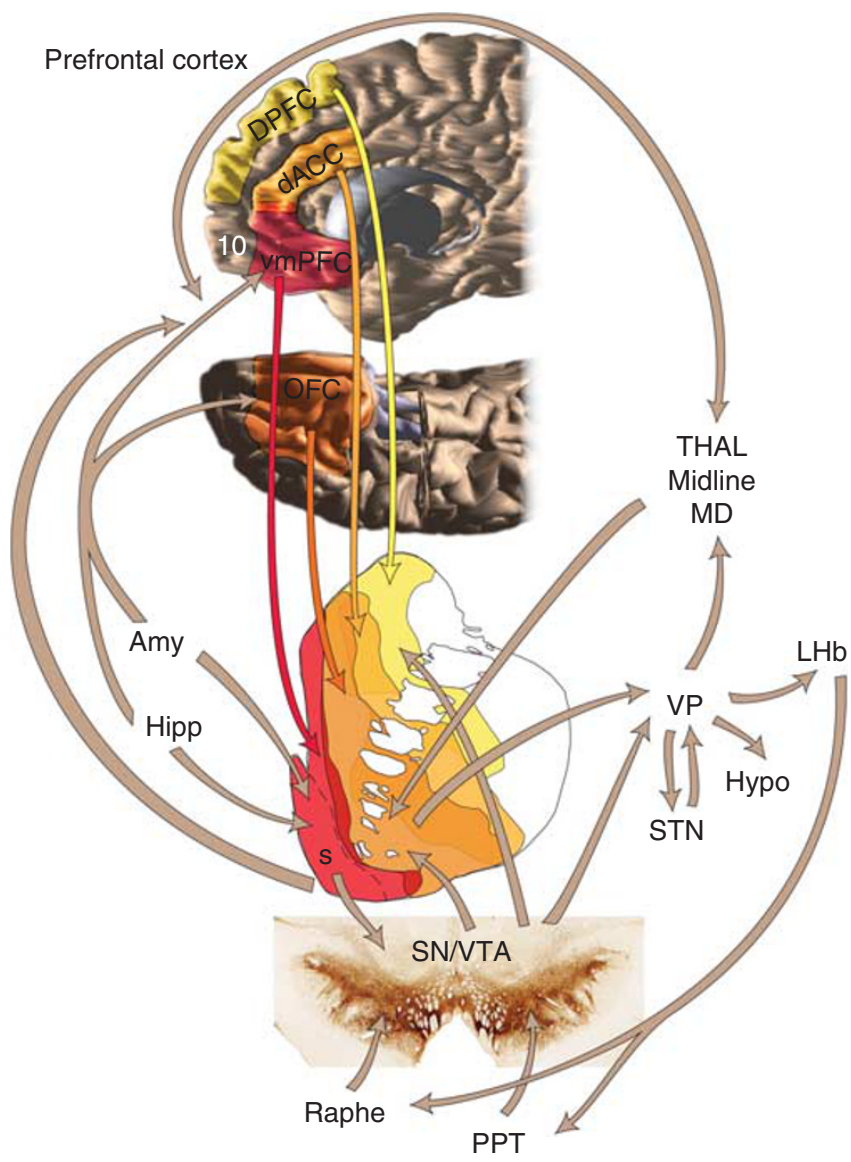

Figure 1. Schematic illustrating key structures and pathways of the reward circuit. Red arrow = input from the vmPFC; dark orange arrow = input from the OFC; light orange arrow = input from the dACC; yellow arrow = input form the dPFC; brown arrows other main connections of the reward circuit. Amy=amygdala; dACC $=$ dorsal anterior cingulate cortex; dPFC = dorsal prefrontal cortex; Hipp= hippocampus; $\mathrm{LHb}=$ lateral habenula; hypo = hypothalamus; OFC = orbital frontal cortex; PPT = pedunculopontine nucleus; $\mathrm{S}=$ shell, $\mathrm{SNc}=$ substantia nigra, pars compacta; STN=subthalamic nucleus.; Thal=thalamus; $\mathrm{VP}=$ ventral pallidum; $\mathrm{VTA}=$ ventral tegmental area; $\mathrm{vmPFC}=$ ventral medial prefrontal cortex.

explosion of such studies that focus on the function of the prefrontal cortex and striatum in reward. These studies use different reward paradigms, methods of analysis, and technologies, creating a complex literature that is often difficult to synthesize. Thus, our goal here is not so much to exhaustively review that literature, but to highlight some promising lines of inquiry based on it. This chapter focuses first on the anatomy (primarily in monkeys). Second, we review functional activation of cortico-basal ganglia reward circuitry to explore points of convergence between primate anatomy studies and human functional MRI studies. Clearly, imaging methods to date do not have the resolution capabilities afforded by animal-tracing studies. Therefore, the anatomical specificity obtained through animal work is not currently possible using functional MRI. However, in each section, we link these studies when possible.

\section{Reward and the Basal Ganglia}

The reward circuit, now considered to be embedded within the cortico-basal ganglia network, is a central component for developing and monitoring motivated behaviors. Historically, however, the basal ganglia were best known for their relevance to motor functions, based both on the neuropathology of movement disorders and the idea that basal ganglia pathways return primarily to motor cortex (Nauta and Mehler, 1966). Our concept of basal ganglia function has dramatically changed in the last 30 years, from a purely motor or sensory-motor function to a more complex set of functions that mediate the full range of goal-directed behaviors, including emotions, motivation, and cognition. The change resulted from several lines of inquiry, but at the center was the demonstration that frontal cortical information passing through the basal ganglia returns to all of the frontal cortex, not only to motor cortex. This idea first arose in the late 1970s with the development of Heimer's classic concept of the VS and VP. The discovery added a separate functional loop, the limbic loop, within the basal ganglia (Heimer, 1978). Subsequently, the anatomical demonstration of this circuit (Haber et al, 1985; Heimer et al, 1982; Young III et al, 1984) provided the evidence for other functional loops (Alexander et al, 1990). The idea of separate cortical loops in the basal ganglia was expanded in primates to include several parallel and segregated circuits based on the finding that each general functional area of cortex (limbic, associative, and sensorimotor) is represented in specific regions in each basal ganglia structure (Alexander et al, 1990; Parent and Hazrati, 1995).

The concept of parallel and segregated functional pathways through the basal ganglia has dominated the field for the past 20 years. However, adaptive behaviors require a combination of reward evaluation, associative learning, and the ability to develop appropriate action plans and inhibit inappropriate choices on the basis of earlier experience. Thus, integration of different aspects of reward processing and interaction of reward circuits and brain regions involved in cognition and motor control are essential. Indeed, the idea of a motivation-to-movement interface through basal ganglia circuits was developed soon after the discovery of the limbic component to the basal ganglia (Heimer et al, 1982; Mogenson et al, 1980; Nauta, 1986). A relatively recent explosion of studies in rodents, monkeys, and humans supports the hypothesis of integration between functional circuits. Together, this literature shows the complexity of the cortico-basal ganglia network and the place of the reward circuit within it. Overall, there appears to be a dual organization that permits both parallel and integrative processing. Thus, the ventral cortico-basal ganglia network, while at the heart of reward processing, does not work in isolation (Belin and Everitt, 2008; Bevan et al, 1997; Brown et al, 1998; Draganski et al, 2008; Haber et al, 2000, 2006; Joel and Weiner, 1994; Kasanetz et al, 2008; Kolomiets et al, 2001; McFarland and Haber, 2002; 
Mena-Segovia et al, 2005; Percheron and Filion, 1991). Indeed, within each station of the circuit, there are pathways that allow communication between different parts of the reward circuit and between the reward circuit and the associative circuit. In this chapter, we first describe the anatomical organization of each of the main structures and points of interaction between circuits before discussing their role in reward, as indicated from human imaging studies.

\section{PREFRONTAL CORTEX}

\section{Organization of Prefrontal Cortex}

Although cells throughout cortex fire in response to rewarding stimuli, the main cortical areas associated with reward are the anterior cingulate cortex and OFC. These are complex and heterogeneous regions, each of which is further divided into specific cortical areas: the anterior cingulate cortex includes areas 24, 25, and 32; the orbital cortex is divided into areas 11, 12, 13, and 14 (Barbas, 1992; Carmichael and Price, 1994; Fuster, 2001; Walker, 1940). Several homologies have been developed primarily based on cytoarchitectonics between monkey human prefrontal cortical areas (Brodmann, 1909; Fuster, 2001; Ongur and Price, 2000; Petrides and Pandya, 1994). Determining these homologies is a complex and difficult task due to the enormous expansion of prefrontal cortex through evolution. Nonetheless, there is reasonable agreement about which cortical areas can be considered homologous. However, cortical labeling in humans and monkeys can differ. Particularly relevant for this chapter is area 11 in the monkey, which is part of the OFC and does not reach the midline, whereas in the human PFC, area 11 does. In contrast, area 14 of the OFC lies on the ventral surface at the midline in monkeys, but may not be a designated area in some human maps. Area 32 occupies a somewhat different position in monkey and human maps. Since imaging studies cannot distinguish between these cortical divisions, they are, therefore, more broadly defined. These prefrontal regions include (1) a caudal, sensory region, which includes parts of both the OFC and insula cortex; (2) a rostral OFC, which includes parts of areas 11,13 , and 12; (3) a ventral, medial PFC (vmPFC), which includes primarily areas 11,10 , and 32 in humans and areas 25,14 , and subgenual area 32 in monkeys; and (4) the dorsal ACC (dACC), area 24. The vmPFC contains a subregion, the medial PFC (mPFC) that is limited to areas 10/32, and does not include medial OFC, area 11 (Knutson et al, 2003). Although some authors include the dACC in a general category of $\mathrm{mPFC}$, others distinguish the dACC from subgenual medial areas (Averbeck and Seo, 2008; Botvinick et al, 1999b; Glascher et al, 2009; Haber et al, 2006; Knutson et al, 2003; Passingham et al, 2002; Petrides et al, 2002). For a more detailed anatomical discussion of these cortical regions, see Price and Drevets in this volume.

\section{Reward Processing in the Human Prefrontal Cortex}

Initial metabolic PET and FMRI studies show that various types of rewards can recruit prefrontal cortical activity. These findings generally suggest that exposure to both primary rewards (eg, pleasant tastes, sounds, and sights) and secondary rewards (eg, monetary gains) increases activity in regions of frontal cortex in general and the vmPFC in particular (Aharon et al, 2001; Anderson et al, 2003; Blood and Zatorre, 2001; Breiter et al, 1997; Elliott et al, 2000b; Knutson et al, 2000; Kunig et al, 2000; Martin-Solch et al, 2001; O’Doherty et al, 2001; Rogers et al, 1999; Rolls et al, 2003; Small et al, 2001; Thut et al, 1997). Importantly, many of these studies control for confounds (eg, perceptual salience, arousal, motor demands), by contrasting neural responses to rewarding stimuli against those punishing stimuli of similar magnitude. Although all of these studies implicate the vmPFC in reward processing, some also implicate activation in dACC and dorsal prefrontal cortices (dPFC).

The region most often associated with reward in monkey physiology studies is the OFC (Padoa-Schioppa and Assad, 2006; Roesch and Olson, 2004; Rolls, 2000; Tremblay and Schultz, 2000; Wallis and Miller, 2003). Consistent with these studies and human lesion findings (Bechara et al, 1994), several neuroimaging studies suggest that sensory and abstract rewards can recruit the OFC. A meta-analysis of these findings uncovered two trends (Kringelbach and Rolls, 2004). First, sensory rewards (eg, juice) tend to activate more posterior OFC regions, whereas more abstract rewards (eg, money) tend to activate more anterior OFC regions. Second, rewards tend to activate medial regions of the OFC (eg, near the gyrus rectus), whereas punishments tend instead to activate more lateral regions of the OFC. Punishments, however, often inhibit ongoing motor responses, which also increases lateral OFC activation (O'Doherty et al, 2003a). More recent evidence suggests that activation in distinct but overlapping lateral OFC regions responds to punishment (more caudal and lateral, closer to the insula) vs motor inhibition (more rostromedial) (Elliott et al, 2000a). Together, these findings implicate the vmPFC in processing of diverse and abstract rewards compared with lateral OFC regions.

The improved temporal resolution of event-related FMRI (Buckner, 1998) allows tracking not only of where reward related activation occurs, but also when it occurs. This opens the possibility of separately examining neural activation during reward anticipation and in response to reward outcomes. For example, rewarding outcomes signaled by sensory cues, including cued pleasant odors (Gottfried et al, 2003) and attractive faces (Bray and O'Doherty, 2007), activate vmPFC. However, a number of studies using abstract rewards (ie, money), rather than sensory ones to measure gain outcomes, found that activation in the mPFC can be distinguished from the larger vmPFC area (Kim et al, 2006; Knutson et al, 2003, 2005; Kuhnen and Knutson, 2005; Yacubian et al, 2006). As 
indicated above, this mPFC region occupies the middle frontal gyrus of the medial wall anterior to the genu of the corpus callosum (ie, at the confluence of Brodmann areas 10 and 32), but not the medial OFC or dACC. Specific responses in the mPFC to gain outcomes have been confirmed with human depth-electrode recordings in a gambling task (Oya et al, 2005). Taken together, these findings are consistent with the speculation that a subregion of vmPFC, specifically the $\mathrm{mPFC}$, may preferentially respond to rewarding outcomes (Daw et al, 2006; Knutson et al, 2003).

Regions of the mPFC also respond to contextual aspects of reward during anticipation. For instance, in FMRI studies of expected value, mPFC activation correlate not only with the anticipated magnitude, but also with the anticipated probability of rewards (Knutson et al, 2005) (Figure 2) (Yacubian et al, 2006). mPFC activation may also weigh benefits against costs when people consider risky investments in the context of financial risk taking (Knutson et al, 2005; Preuschoff et al, 2006) and might do so by integrating input from the VS and insula (Bruguier et al, 2008). mPFC activation further correlates not only with anticipated magnitude of monetary gains, but also their immediacy in the context of temporal discounting (Ballard and Knutson, 2009; Kable and Glimcher, 2007; McClure et al, 2004a). Finally, mPFC activation correlates with the additional value of a product's price in the context of purchasing, consistent with the economic notion of 'consumer surplus' (Knutson et al, 2007; Plassmann et al, 2007). Interestingly, mPFC

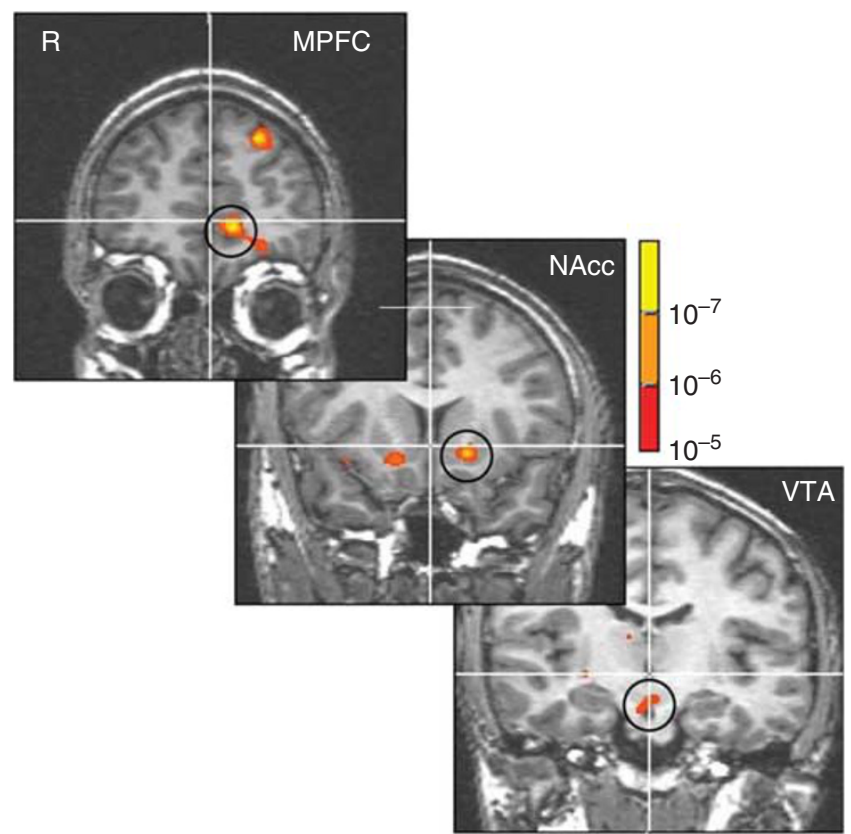

Figure 2. Expected value of monetary rewards activates the ventral cortico-basal ganglia circuit. Panels indicate activation significantly correlated with expected value in the mPFC (anterior $=45$ ), NAcc (anterior $=12$ ), and VTA (anterior $=-15$ ). Although the midbrain and VS are sensitive to anticipated reward magnitude, the MFPC is also sensitive to anticipated reward probability (not shown here; adapted from Knutson et al, 2005). activation clearly tracks value rather than number, as its activation decreases in response to (undesirable) high prices in the context of buying, but increases in response to (desirable) high prices in the context of selling (De Martino et al, 2009; Knutson et al, 2008). Together, these findings suggest that $\mathrm{mPFC}$ activation may integrate value across different stimulus dimensions or different stimuli (Blair et al, 2006). This integrative account is consistent with responsiveness to reward outcomes, as these outcomes invoke a shift in the representation of reward probability after magnitude has been established. Although value integration can occur later, or even in the absence of choice, it can also occur before choice (Glascher et al, 2009; Knutson et al, 2007), thus carrying the potential to inform upcoming decisions.

The dACC and APFC also play important roles in reward processing, though not in ways that translate directly to valuation. The AACC is a unique part of frontal cortex. It contains a representation of diverse frontal lobe functions, including motivation, cognition, and motor control. This diversity is consistent with widespread connections with other affective, cognitive, and motor cortical areas. Despite this complexity, the overall function of the dACC seems to involve monitoring these functions in potential conflict situations (Botvinick et al, 1999a; Paus, 2001; Vogt et al, 2005; Walton et al, 2003). Conflict monitoring should prove important when comparing similarly valued options. In addition to the dACC and vmPFC, the dPFC (particularly areas 9 and 46) are engaged when working memory is required for monitoring incentive-based behavioral responses. Both lesion and neuroimaging findings implicate the $\mathrm{dPFC}$ in working memory (Fletcher and Henson, 2001), and this capacity should prove most critical when multiple options must be held in mind for evaluation, comparison, and selection. Thus, the dACC and APFC may work together in a complementary manner to compare valued options, choose among them, and channel that choice into a course of action that promotes acquiring the most valuable option (MacDonald et al, 2000; Ridderinkhof et al, 2004). Indeed, this line of reasoning is consistent with the observation that consideration of highly valued options elicits increased dorsolateral prefrontal cortical activation in purchasing scenarios (Knutson et al, 2007; Plassmann et al, 2007). On the other hand, consideration of options that conflict on different dimensions (eg, high preference, but high price) increases dACC activation in investing and purchasing scenarios (without necessarily predicting choice) (Knutson et al, 2007; Kuhnen and Knutson, 2005).

\section{VENTRAL STRIATUM}

\section{Organization of the VS}

The concept of the VS was originally developed by Heimer in 1978 in the classic paper in which he describes the 
relationship between the NAcc and the olfactory tubercle in rats (Heimer, 1978). The link between NAcc activity and reward had already been established as part of the selfstimulation circuit originally described by Olds and Milner (Olds and Milner, 1954). Since the identification of the VS, our concept of the striatal region associated with reward has evolved to include this extended region, expanding the traditional boundary of the NAcc. This entire region has been a focus for the study of reinforcement and the transition between drug use for a reward and as a habit (Bowman et al, 1996; Drevets et al, 2001; Jensen et al, 2003; Kalivas et al, 2005; Lyons et al, 1996; Parkinson et al, 2000; Schultz et al, 1992; Taha and Fields, 2006). In human and nonhuman primates, the VS includes the NAcc and the broad continuity between the caudate nucleus and the putamen ventral to the rostral internal capsule, the olfactory tubercle, and the rostrolateral portion of the anterior perforated space adjacent to the lateral olfactory tract (Haber and McFarland, 1999; Heimer et al, 1999). Importantly, however, neither cytoarchitectonic nor histochemistry distinctions mark a clear boundary between the VS and the dorsal striatum, which poses a problem for defining locations of activation in imaging and animal studies. Perhaps, the best way, therefore, to define the VS is by its afferent projections from cortical areas that mediate different aspects of reward and emotional processing, namely the vmPFC, OFC, dACC, and the medial temporal lobe, including the amygdala. Using these projections as a guide, the VS occupies over $20 \%$ of the striatum in nonhuman primates (Haber et al, 2006). As a subcomponent of the VS, the term NAcc is best described by a small ventromedial sector in the rostral striatum that receives input from specific cortical regions (see below).

Special features of the VS. Although the VS is similar to the dorsal striatum in most respects, there are also some unique features. Within the NAcc region of the VS, a subterritory, called the shell, has a particularly important function in the circuitry underlying goal-directed behaviors, behavioral sensitization, and changes in affective states (Carlezon and Wise, 1996; Ito et al, 2004). Although several transmitter and receptor distribution patterns distinguish the shell/core subterritories, calbindin is the most consistent marker for the shell across species (Alheid and Heimer, 1988; Ikemoto et al, 1995; Martin et al, 1993; Meredith et al, 1996; Sato et al, 1993). The shell has some unique connectivities that distinguish it from the rest of the VS (indicated below). However, while animal studies have distinguished the shell from the rest of the striatum, the spatial resolution in imaging studies is not yet sufficient to isolate this region in humans.

In addition to the shell compartment, several other characteristics are unique to the VS. The dopamine transporter (DAT) is relatively low in the VS compared to the dorsal striatum. This pattern is consistent with the fact that the dorsal tier dopamine neurons (which project to the VS) express relatively low levels of mRNA for the DAT compared to the ventral tier (which project to the dorsal striatum) (Counihan and Penney, 1998; Haber et al, 1995b; Harrington et al, 1996) (see section Amygdala). The VS has numerous smaller and more densely packed neurons; the dorsal striatum is more homogenous. The VS contains cell islands, including the islands of Calleja, which are thought to contain quiescent immature cells that remain in the adult brain (Bayer, 1985; Chronister et al, 1981; Meyer et al, 1989). The VS also contains many pallidal cells and their dendritic arbors that invade this ventral forebrain territory (see section Ventral pallidum). Finally, and of particular importance, is the fact that while both the dorsal and VS receive input from the cortex, thalamus, and brainstem, the VS alone receives a dense projection from the amygdala and hippocampus (Friedman et al, 2002; Fudge et al, 2002; Russchen et al, 1985).

Connections of the VS (Figure 3). Afferent projections to the VS, like those to the dorsal striatum are derived from three major sources: a massive, generally topographic glutamatergic input from cerebral cortex; a large glutamatergic input from the thalamus; and a smaller, but critical input from the brainstem, primarily from the midbrain dopaminergic cells. Although this section primarily focuses on the connections of the VS, it gives some attention to the dorsal striatum, especially the caudate nucleus, an area that is also involved in reward-based learning (Cromwell and Schultz, 2003; Kennerley and Wallis, 2009; Watanabe and Hikosaka, 2005). This region receives input from the dPFC.

Cortical projections. Cortico-striatal projections form dense, focal patches that can be visualized at low magnification. These terminal projections are organized in a functional topographic manner (Parent and Hazroti, 1995): the dorsolateral striatum receives cortical input from sensory-motor areas; the central striatum receives input from associative cortical areas; and the VS receives input from limbic areas. Within each general functional region (limbic, associative, and motor), terminals are also topographically organized. Thus, inputs from the vmPFC, OFC, and dACC terminate within subregions of the VS, and the $\mathrm{dPFC}$ terminates primarily in the caudate nucleus (Haber et al, 1995a; Selemon and Goldman-Rakic, 1985). The focal projection field from the vmPFC is the most limited. It is concentrated within the NAcc, including the shell (Figures $4 \mathrm{a}$ and 5). The vmPFC also projects to the medial wall of the caudate nucleus, adjacent to the ventricle. The densest input from agranular insular cortex also terminates in the NAcc and at the medial wall of the caudate (Chikama et al, 1997). Less data is available concerning the projections of area 10 to the VS, particularly medial area 10 . However, tracer injections into dorsal and lateral area 10 project to the medial wall of the rostral caudate (overlapping with inputs from the vmPFC) (Ferry et al, 2000). Based on these data, one might assume that the medial and ventral area 10 (an area included in the $\mathrm{mPFC}$ in the imaging studies described above) would terminate in the NAcc. Thus, the NAcc in primates receives 


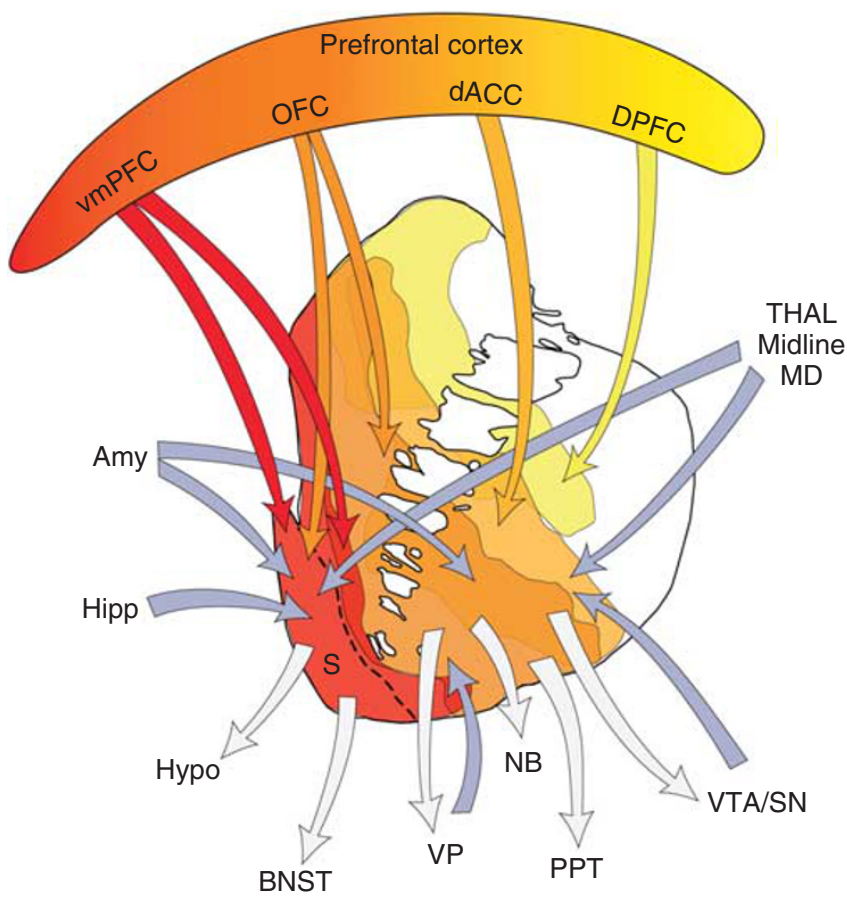

Figure 3. Schematic illustrating the connections of the VS. Blue arrows = inputs; gray arrows = outputs; Amy=amygdala; BNST $=$ bed nucleus stria terminalis; $\mathrm{dACC}=$ dorsal anterior cingulate cortex; Hipp = hippocampus; hypo = hypothalamus; $\mathrm{MD}=$ medio-dorsal nucleus of the thalamus; $\mathrm{OFC}=$ orbital frontal cortex; PPT = pedunculopontine nucleus; $\mathrm{S}=$ shell; $\mathrm{SNc}=$ substantia nigra, pars compacta; $\mathrm{STN}=$ subthalamic nucleus; Thal =thalamus; $V P=$ ventral pallidum; $V S=$ ventral striatum; $\mathrm{VTA}=$ ventral tegmental area; $\mathrm{vmPFC}=$ ventral medial prefrontal cortex.

convergent input from the olfactory and visceralassociated insula, from the vmPFC, and most likely from area 10.

The dorsal and lateral parts of the VS (the ventral caudate nucleus and putamen) receive inputs from the OFC (Figures $4 \mathrm{~b}$ and 5). These terminals also extend dorsally, along the medial caudate nucleus, but lateral to those derived from the vmPFC. The medial to lateral and rostral to caudal topographic organization of the OFC terminal fields is consistent with the positions of OFC regions in the PFC. That is, inputs from lateral parts of the OFC (ie, area 12) terminate lateral to those derived from more medial areas (area 13). For the most part, fibers from the OFC terminate lateral to the NAcc. Finally, projections from the dACC extend from the rostral pole of the striatum to the anterior commissure and are located in the rostral, central caudate nucleus and central putamen (Figures $4 c$ and 5). These terminals primarily avoid the NAcc, terminating somewhat lateral to those from the OFC. Taken together, the vmPFC, $\mathrm{OFC}$, and dACC project primarily to the rostral striatum, with the vmPFC projecting most medially (to the NAcc) and the dACC most laterally (Haber et al, 2006), with the OFC terminal fields positioned between them. In contrast, the dPFC projects throughout the rostrocaudal extent of the striatum, terminating primarily in the head of the caudate and in part of the rostral putamen (Figures $4 \mathrm{~d}$ and 5), a
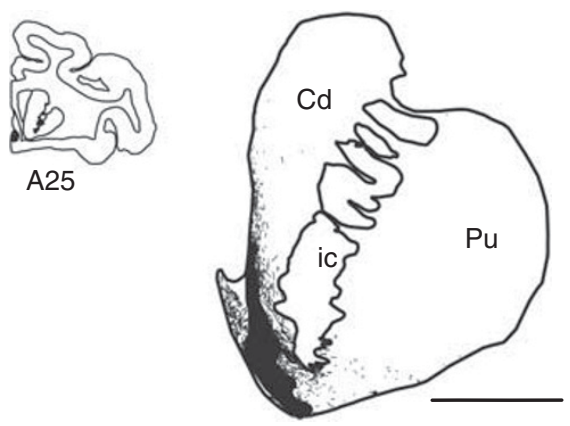

b
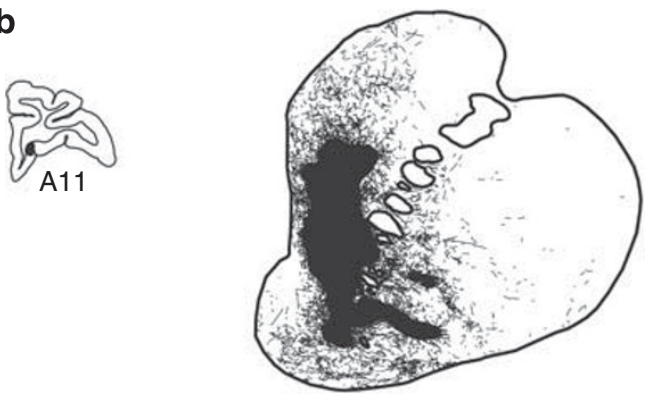

C
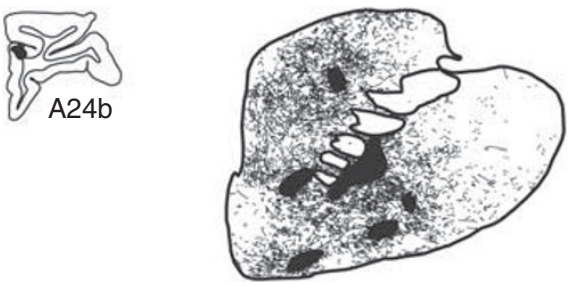

d
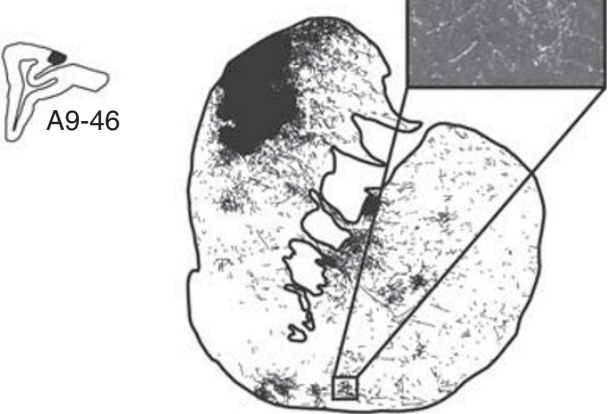

Figure 4. Schematic chartings of labeled fibers after injections into different prefrontal regions. (a) vmPFC injection site (area 25), (b) OFC injection site (area 11), (c) dACC, (d) dPFC injection site (area 9/46). The focal projection fields are indicated in large solid black shapes. Diffuse projection fibers are found outside of the focal projection fields (as illustrated in the photomicrograph in (d)).

but continuing into the caudal caudate nucleus. For the anatomical details concerning prefrontal corticostriatal projections, see Haber et al (1995a) and Selemon and Goldman-Rakic (1985).

Intergration between cortico-striatal projections. Although the topographic organization of cortico-striatal projections is well documented, there is increasing evidence for regions 

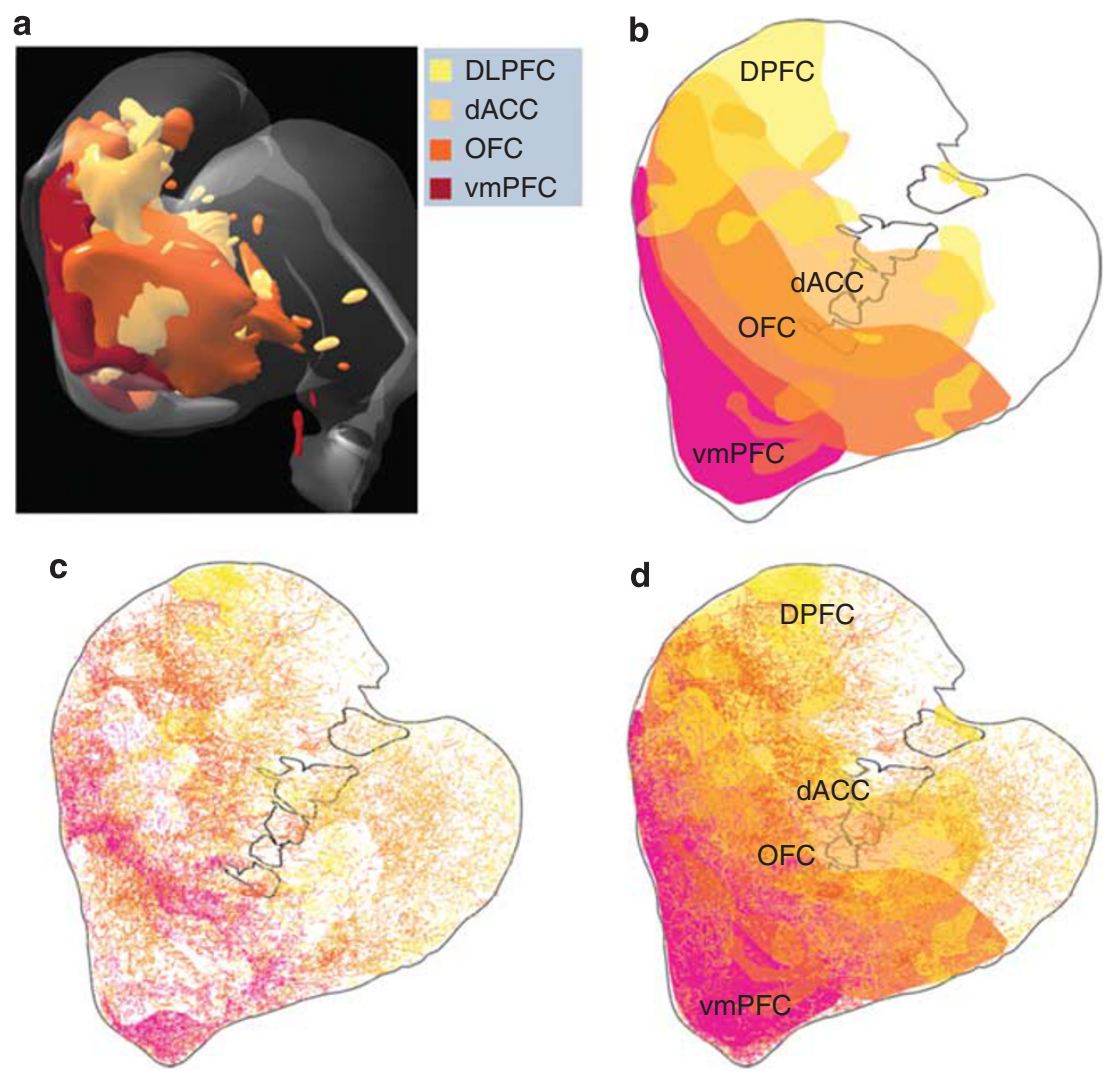

Figure 5. Schematics showing convergence of cortical projections from different reward-related regions and dorsal prefrontal areas. (a) Medio-frontal view of a 3D reconstruction illustrating convergence of inputs from PFC inputs. (b) 2D section through the striatum illustrating regions of convergence. (c) Distribution of diffuse fibers from different PFC regions. (d) Diffuse fibers are superimposed onto the focal projections, showing the interface between diffuse and focal projections. $\mathrm{ACC}=$ dorsal anterior cingulate cortex; $\mathrm{dPFC}=$ dorsal lateral prefrontal $\operatorname{cortex}$; $\mathrm{OFC}=$ orbital prefrontal cortex; $\mathrm{vmPFC}=$ ventral medial prefrontal cortex. red $=$ inputs from vmPFC; dark orange $=$ inputs from OFC; light orange $=$ inputs from dACC; yellow $=$ inputs from dPFC.

of interface between terminals from different cortical areas, suggesting functional integration. For example, early studies showed that cortico-striatal terminals from sensory and motor cortex converge within the striatum (Flaherty and Graybiel, 1993). Here, axons from each area synapse onto single fast spiking GABAergic interneurons. Interestingly, these interneurons are more responsive to cortical input than the medium spiny cells (Charpier et al, 1999; Mallet et al, 2005; Ramanathan et al, 2002; Takada et al, 1998). This suggests a potentially critical role for interneurons to integrate information from different cortical areas before passing that information onto the medium spiny projection cells.

Recent studies reveal that projections from the OFC, vmPFC, and dACC also converge in specific regions within the VS. Thus, focal terminal fields from the vmPFC, OFC, and AACC show a complex interweaving and convergence, providing an anatomical substrate for modulation between these circuits (Haber et al, 2006) (Figure 5a and b). For example, in certain regions, the vmPFC projection field converges with that from the OFC. Moreover, projections from the dACC and OFC regions do not occupy completely separate territories in any part of the striatum, but converge most extensively at rostral levels. In addition, projections from dACC and OFC also converge with inputs from the $\mathrm{dPFC}$, particularly at the most rostral striatal levels. A similar pattern of both topographic and integrative connectivity of cortico-striatal projections has been demonstrated in the human brain using diffusion tensor imaging (DTI). These data show a similar overall organization of the different cortical regions and the striatum, providing a strong correlation between monkey anatomical-tracing studies and human DTI studies (Draganski et al, 2008). Taken together, a coordinated activation of $\mathrm{dPFC}$, dACC, and/or OFC terminals in these subregions could produce a unique combinatorial activation at the specific sites for channeling reward-based incentive drive in selecting between different valued options. Functional imaging studies do not, at this time, have the resolution to specifically detect these convergence zones. Nonetheless, the fact that these areas exist may help explain complex activation patterns following different reward-related paradigms described below.

In addition to focal projection fields described above, the cortex also has a diffuse projection system to the striatum. Based on intracellular tracer injections into individual neurons, cortico-striatal axons have been shown to travel some distance (Parent and Parent, 2006; Zheng and Wilson, 
2002), invading striatal regions that receive their focal input from other prefrontal cortex areas (Figure 4). Collectively, the diffuse projections from each cortical area consist of clusters of terminal fibers that are widely distributed throughout the striatum, not only expanding the borders of the focal terminal fields, but also extending throughout other regions of the striatum (Haber et al, 2006). For example, the diffuse projection from the vmPFC extends lateral and dorsal to its focal projection field. The diffuse OFC fibers extend deep into the dorsal caudate, central caudate, and putamen, with extensive convergence with both focal and diffuse projections from the dACC and the dPFC (Figure 4b). Finally, clusters of dPFC fibers terminate throughout the rostral striatum, including the VS. Thus, the diffuse fiber system constitutes a large population of axons invading each focal projection field. Under certain conditions, if collectively activated, they may provide the recruitment strength necessary to modulate striatal activity by broadly disseminating cortical information. This relatively low level of modulation may provide an anatomical substrate for cross-encoding information to influence the future firing of medium spiny neurons (Kasanetz et al, 2008), playing an important role in the temporal activation of different striatal regions during learning. Taken together, the fronto-striatal network constitutes a dual system comprising both topographically organized terminal fields and subregions that contain convergent pathways derived from functionally discrete cortical areas (Draganski et al, 2008; Haber et al, 2006).

The amygdala and hippocampal projections to the VS. Overall, the basal nucleus and the magnocellular division of the accessory basal nucleus are the main source of inputs to the VS (Fudge et al, 2002; Russchen et al, 1985). The lateral nucleus has a relatively minor input to the VS. The amygdala has few inputs to the dorsal striatum in primates. Although the basal and accessory basal nuclei innervate both the NAcc and the larger regions of the VS striatum, the densest projection appears to be within the NAcc. The shell of the NAcc, however, is set apart from the rest of the VS by a specific set of connections derived from the medial part of the central nucleus (CeM), periamygdaloid cortex, and the medial nucleus of the amygdala. In contrast to the amygdala, the hippocampal formation projects to a more limited region of the VS, primarily derived not only from the subiculum, but also from the parasubiculum and part of CA1 (Friedman et al, 2002). The main terminal field is located in the most medial and ventral parts of the VS and is essentially confined to the NAcc shell. Here, these inputs overlap with those from the amygdala and from the vmPFC. Taken together, the existence of convergent fibers from cortex within the VS, along with hippocampal and amygdalo-striatal projections, places the VS as a key entry port for processing emotional and motivational information that, in turn, drives basal ganglia action output (see Sesack and Grace in this volume). Within the VS, the NAcc receives the densest innervation from the amygdala, hippocampus, and the vmPFC.

Thalamic projections to the VS. The midline and medial intralaminar thalamic nuclei project to medial prefrontal areas, the amygdala, and hippocampus. As such, they are referred to as the limbic-related thalamic nuclear groups (Akert and Hartmann-von Monakow, 1980; Yakovlev et al, 1960). These nuclei also project to the VS (Berendse and Groenewegen, 1990; Giménez-Amaya et al, 1995). As seen with the cortical projections, the NAcc receives the most limited input, which is derived almost exclusively from the midline nuclei. The medial wall of the caudate nucleus receives projections, not only from the midline and the medial intralaminar nuclei, but also from the central superior lateral nucleus. In contrast, the lateral part of the VS receives a limited projection from the midline thalamic nuclei. Its input is mainly from the intraliminar nuclei (the parafascicular nucleus and the central superior lateral nucleus). In addition to the midline and intralaminar thalamo-striatal projections, in primates, there is a large input from the 'specific' thalamic-basal ganglia relay nuclei, the $\mathrm{MD}$, ventral anterior, and ventral lateral nuclei (McFarland and Haber, 2001). The VS receives this input from the medial MD nucleus and a limited projection from the magnocellular subdivision of the ventral anterior nucleus.

Efferent projections from the VS. The VS, like those to the dorsal striatum, projects primarily to the pallidum and midbrain (Haber et al, 1990a; Hedreen and DeLong, 1991; Parent et al, 1997) (Figure 3). Specifically, fibers terminate topographically in the subcommissural VP, the rostral pole of the external segment, and the rostromedial portion of the internal segment (see section Ventral pallidum). The more central and caudal portions of the globus pallidus do not receive this input. Fibers from the VS projecting to the midbrain are not as confined to as specific a region as those projecting to the pallidum. Although the densest terminal fields are in the medial portion (VTA and medial $\mathrm{SN}$ ), numerous fibers also extend laterally to innervate the entire dorsal tier of the midbrain dopaminergic neurons (see section Midbrain Dopamine Neurons for a more detailed discussion on the SN). Projections from the medial part of the VS continue more caudally, terminating in the pedunculopontine nucleus. In addition to these projections, the VS also terminates in nonbasal ganglia regions (Haber et al, 1990a; Zahm and Heimer, 1993). The shell sends fibers caudally and medially into the lateral hypothalamus and, to some extent, in the periaqueductal gray. Axons from the medial VS (including the shell) also terminate in the bed nucleus of the stria terminalis, indicating a direct striatal influence on the extended amygdala (see Davis and Grillon in this volume). Finally, axons from ventral regions of the VS terminate in the nucleus basalis. This connection has been demonstrated at the light microscopic level in monkeys and verified at the 
EM level in rodents (Beach et al, 1987; Chang et al, 1987; Haber, 1987; Martinez-Murillo et al, 1988; Zaborszky and Cullinan, 1992). A projection to the nucleus basalis in the basal forebrain is of particular interest, since this is the main source of cholinergic fibers to the cerebral cortex and the amygdala. These data indicate that the VS may influence cortex directly, without going through the pallidal and thalamic circuit. This may provide a route through which reward circuit has access to a wider region of frontal cortex than via the more confined ventral cortico-basal ganglia circuit.

\section{Reward Processing in the Human VS}

To localize striatal activation, researchers have devised structural schemes that distinguish ventral from dorsal striatum in the case of PET or NAcc from caudate and putamen in the case of FMRI (Breiter et al, 1997; Drevets et al, 2001; Mawlawi et al, 2001) (Figure 6). These schemes are based on anatomical landmarks that define more restricted areas than the patterns of connectivity described above. For instance, based on the primate anatomy reviewed above, inputs to the region labeled as VS (upper panel) likely come from the vmPFC, amygdala, and the hippocampus, and some, but not all, from OFC regions (particularly the more lateral OFC areas). The region labeled as the NAcc (lower panel) is smaller and likely receives a more limited subset of inputs from the vmPFC and amygdala. However, it receives most of its input from the $\mathrm{mPFC}$ and hippocampus. Connectivity studies (as indicated above) suggest that the VS encompasses a larger region, which includes the medial caudate nucleus and rostroventral putamen along with the NAcc. Thus, here the term VS refers the NAcc, the ventral medial caudate, and the rostroventral putamen. Mention of any of these subcomponents alone implies a more specific focus on activation in that region, but does not exclude the possibility of activation in other ventral striatal subcomponents.

Both metabolic and ligand-based PET studies have shown recruitment of striatal regions during reward processing. For instance, metabolic PET studies suggest that exposure to both primary (ie, pleasant tastes and sounds) and secondary rewards (ie, monetary gambles) can increase striatal activity (Blood and Zatorre, 2001; Kunig et al, 2000; Martin-Solch et al, 2001; Small et al, 2001). Similarly, initial FMRI studies of reward processing have also shown that both primary (ie, pleasant tastes, smells, sights, sounds, and touch) and secondary (ie, monetary gain) rewards could increase striatal activation, consistent with the notion that striatal activation does not depend on sensory modality (Aharon et al, 2001; Anderson et al, 2003; Delgado et al, 2000; Elliott et al, 2000b; Gottfried et al, 2002; Knutson et al, 2000; Menon and Levitin, 2005; Mobbs et al, 2003; O'Doherty et al, 2001; Rolls et al, 2003). As with studies of the frontal cortex, many of these studies also included unpleasant and neutral stimuli, thus controlling for arousal and other confounds (eg, perceptual and behavioral demands). Owing to either reduced temporal resolution or temporally nonspecific questions, however, these studies did not establish when neural activation occurred during reward processing.

Although it has similar spatial resolution and less temporal resolution than metabolic PET (ie, on the order of hours), ligand-based PET confers a unique advantage of supporting inference about dopamine release in the striatum. Relative to placebo injection, amphetamine injection robustly increases striatal dopamine (inferred from radioactive ligand displacement), and these increases can correlate with positive and arousing affective experience (eg, feelings of 'euphoria') (Drevets et al, 2001; Leyton et al, 2002; Martinez et al, 2003; Volkow et al, 1999). Consumption of alcohol and cocaine also increase dopamine release in the VS (Boileau et al, 2003; Cox et al, 2009). Secondary rewards such as playing videogame and gambling may also
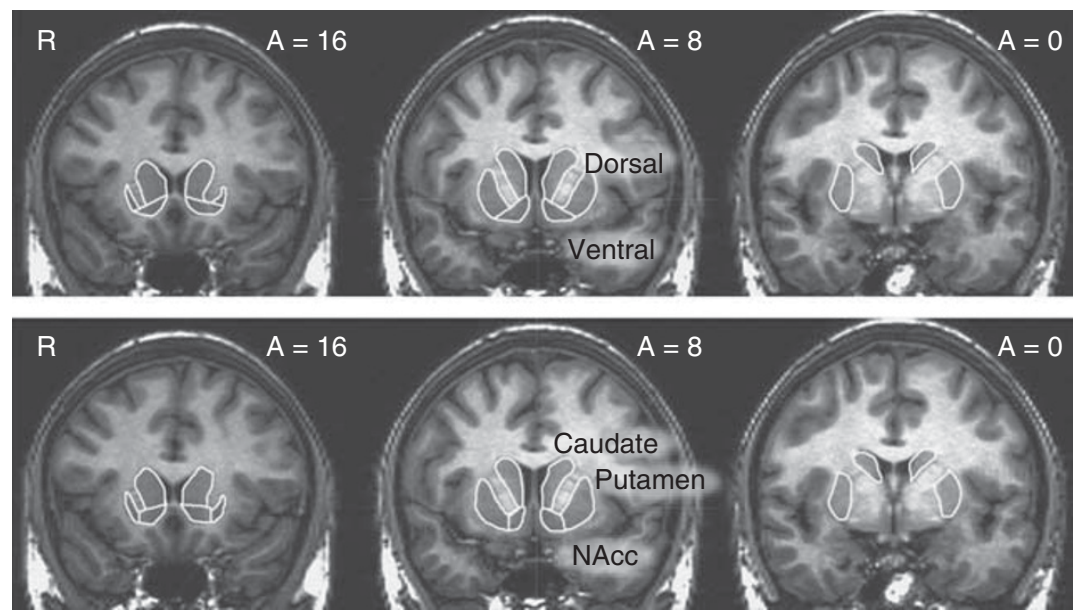

Figure 6. Anatomical schemes for parcellating the striatum based on structural landmarks. Top: Ventral and dorsal striatum (adapted from Mawlawi et al, 2001); Bottom: nucleus NAcc, caudate, and putamen (adapted from Breiter et al, 2001). 
increase dopamine release in parts of the striatum, albeit less consistently and robustly (Koepp et al, 1998; Pappata et al, 2002; Zald et al, 2004).

Event-related FMRI enabled researchers to track changes in striatal activity during different phases of reward processing. This increased temporal specificity coincided with an increase in the number of FMRI studies documenting ventral striatal activation. For instance, in the case of primary rewards, anticipation of a pleasant (but not an unpleasant) taste elicits ventral striatal and OFC activation, whereas the pleasant taste itself elicits only OFC activation (O'Doherty et al, (2002). In the case of secondary rewards, anticipation of uncertain monetary rewards (but not punishments) increases NAcc activation, whereas obtaining ( $v s$ not obtaining) rewards increased MPFC activation and kept putamen activation from decreasing (Breiter et al, 2001; Knutson et al, 2001b, 2003).

Anticipated reward can vary along many dimensions, including magnitude, probability, uncertainty, delay, and effort. NAcc activation in these and other imaging studies clearly increases proportional to the magnitude of anticipated monetary reward (Knutson et al, 2001a; Yacubian et al, 2006) (Figure 2). Although medial caudate and MD thalamic activation also increases proportional to the magnitude of anticipated reward, they additionally increased proportional to the magnitude of anticipated punishment. A recent meta-analysis of over 20 similar FMRI studies has confirmed preferential activation of the NAcc during anticipation of monetary gains, but not during anticipation of losses (Knutson and Greer, 2008). Depthelectrode recordings of epileptic patients gambling have also shown that NAcc activity increases proportional to the magnitude of anticipated reward (Cohen et al, 2009a). This proportional response to anticipated reward magnitude provided an anchor for exploring the impact of varying other attributes of anticipated reward. An increasing number of subsequent studies have focused on whether other aspects of anticipated reward besides magnitude might increase NAcc activation (eg, probability, uncertainty, delay and effort).

Probability refers to the likelihood that an anticipated reward will occur, and individuals usually value rewards with high probabilities. Probability can be related to uncertainty, as moderate ranges of probability can imply maximum uncertainty about an outcome (eg, 50\% probability is least informative about whether a given outcome will occur or not occur). During reward anticipation, ventral striatal activation has been reported to track uncertainty in some studies, but probability in other studies. For instance, some studies find that VS activation peaks at intermediate probability levels, consistent with maximal uncertainty (Cooper and Knutson, 2008; Dreher et al, 2006; Knutson et al, 2005; Preuschoff et al, 2006). Other studies, however, have reported linear effects of anticipated reward probability on VS activation (Abler et al, 2006; Hsu et al, 2009; Tobler et al, 2008; Yacubian et al, 2006). A large subsequent study investigated the possibility that different subcomponents within the VS showed greater sensitivity to anticipated reward magnitude $v s$ probability (Yacubian et al, 2007). Although peak responsiveness to magnitude occupied the NAcc and medial caudate, peak responsiveness to probability occupied the rostroventral putamen, suggesting differential sensitivity to anticipated reward magnitude $v$ s probability in different VS subcomponents (see also Preuschoff et al, 2006; Tobler et al, 2007).

Delay refers to the amount of time until an anticipated reward can be obtained, and individuals usually devalue or 'discount' rewards with long delays. Initial FMRI studies found evidence that VS activation increased when immediate $v s$ delayed rewards were considered and decreased with the delay of future rewards (Kable and Glimcher, 2007; McClure et al, 2007; McClure et al, 2004a). A subsequent study separately examined VS responses to information about the magnitude and delay of future rewards and found that while NAcc activation alone increased with the magnitude of a future rewards, activation in frontal regions (eg, $\mathrm{mPFC}$ and $\mathrm{dPFC}$ ) instead showed sensitivity to the delay of future rewards (Ballard and Knutson, 2009).

Effort refers to how much an individual must work to get an anticipated reward, and individuals usually devalue rewards that require substantial effort. Investigators have also examined the influence of anticipated effort on VS activation. They found that while anticipated reward magnitude increased NAcc and medial caudate activation, anticipated reward effort decreased activation in a partially overlapping region of the rostroventral putamen (Croxson et al, 2009) (see also Botvinick et al, 2009). Together, these studies raise the possibility that while anticipated reward magnitude consistently increases NAcc and medial caudate activation, other aspects of anticipated value (eg, anticipated probability and effort) may elicit more pronounced activation in the rostroventral putamen subcomponent of the VS.

Within the VS, overlap between these regions may combine distinct aspects of anticipated reward. The findings also raise the possibility of a temporal flow of information through the VS to the dorsal striatum. If the NAcc is recruited early during reward prediction, it may respond to relatively basic information about reward magnitude, whereas other considerations may influence reward processing as activation moves dorsolaterally through the striatum, perhaps as a function of integration of information from prefrontal circuits (Figure 7). Such a dynamic flow of information might occur either through cortico-striatal connections as described in the earlier section or through striato-nigral-striatal connections (described below) or both.

Other research has focused on neural responses to reward outcomes (ie, when potential, but uncertain rewards are obtained or lost). Several studies have associated activation of the medial caudate portion of the VS with rewarding ( $v s$ nonrewarding) outcomes (Delgado et al, 2003, 2000). The medial caudate likely receives inputs from a combination of vmPFC, OFC, dACC, and possibly dPFC. This region 

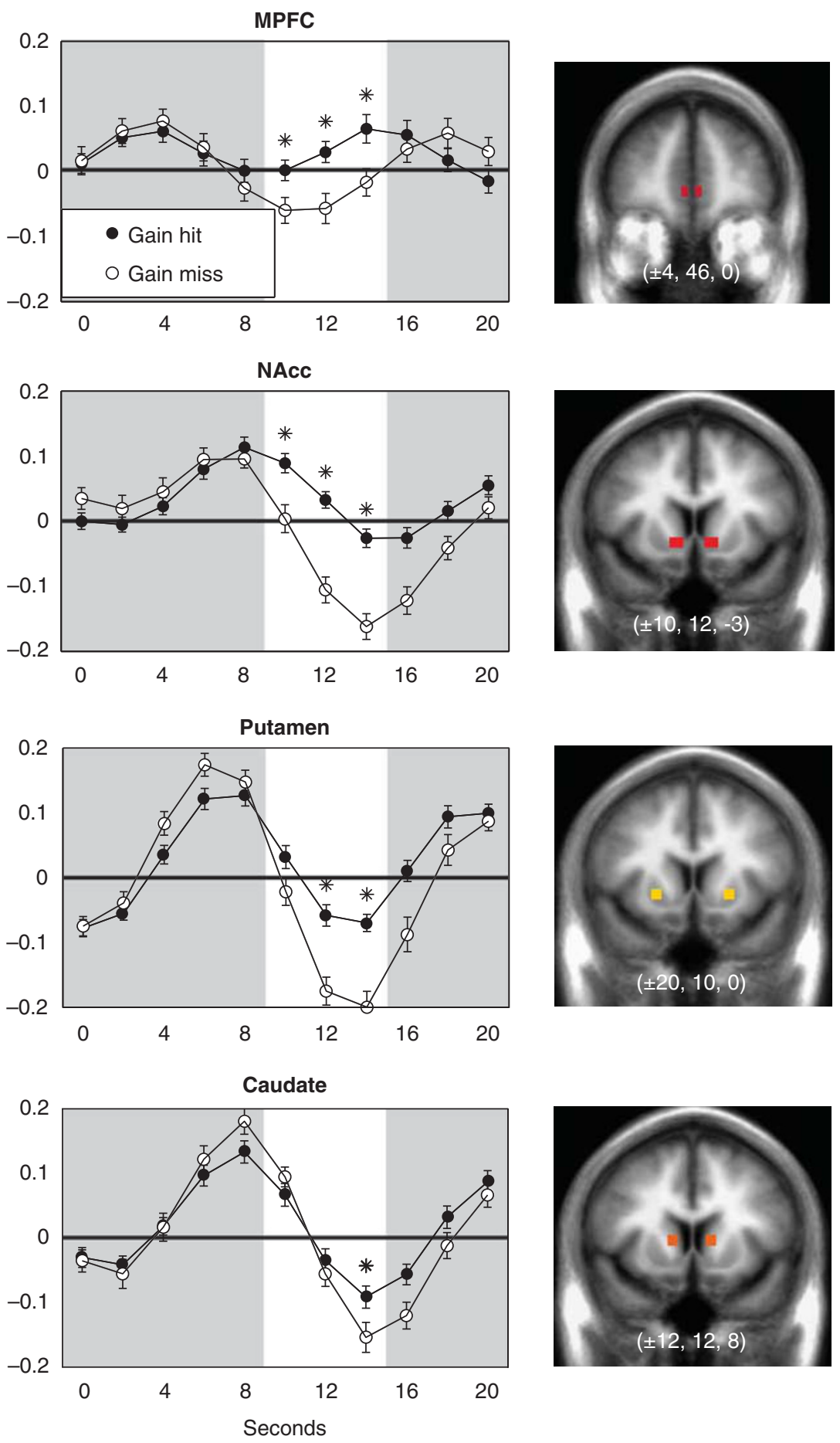

Figure 7. Propagation of gain prediction error from rostral to dorsal striatal regions over time. Lines depict neural responses to gain (+ $\$ 5.00 ;$ black) vs nongain (+\$0.00; gray) outcomes during trials in which subjects had earlier anticipated winning an uncertain large gain (ie, $\$ 5.00$ with $66 \%$ chance of hitting) in the monetary incentive delay task (Knutson et al, 2003). The white band indicates the onset of gain vs nongain feedback (lagged by $4 \mathrm{~s}$ to account for the hemodynamic delay). Stars indicate a significant difference between activation for gain vs nongain feedback ( $p<0.01)$. Note that gain prediction error differences appear in the mPFC and NAcc immediately, but not in the dorsomedial caudate until $2 \mathrm{~s}$ later, and not in the putamen until $4 \mathrm{~s}$ later ( $n=40$ subjects, unpublished data).

responds to relative as well as absolute reward outcomes (ie, when an individual compares what she received to what she might have, but did not receive) (Kuhnen and Knutson, 2005; Lohrenz et al, 2007; Nieuwenhuis et al, 2005). These findings share similarities to an earlier literature suggesting that 'cognitive' feedback can elicit caudate activation (Elliott et al, 1997; Poldrack et al, 1999). Moreover, it establishes that rewards can enhance this activation (Tricomi et al, 
2006). Outcome-elicited medial caudate activation may promote choice of the next best action, as it is most prominent when reward feedback informs subsequent actions (O'Doherty et al, 2004) and decreases as action requirements become more predictable (Delgado et al, 2005). Taken together, the anatomy and imaging data supports the idea that the medial caudate may integrate information from reward and cognitive cortical areas in the development of strategic action planning.

Reward outcomes can also influence VS activation. Specifically, several studies indicate that omission ( $v s$ delivery) of expected rewards can decrease VS activation (Berns et al, 2001; Knutson et al, 2001b; Ramnani et al, 2004). Given that reward anticipation can increase, and nonreward outcomes can decrease, VS activation, theorists have proposed that VS activity tracks a reward prediction error (or the difference between expected and obtained rewards) (McClure et al, 2007; Montague et al, 1996; Schultz et al, 1997). Indeed, computational modeling of brain activity during reward learning indicates that a reward prediction error term correlates with activity in the rostroventral putamen (McClure et al, 2003; O'Doherty et al, 2003b). As the NAcc and medial caudate subcomponents robustly activate during reward anticipation, and the rostroventral putamen most reliably deactivates in response to nonreward delivery, it remains to be established whether common or distinct subcomponents of the VS respond to both events. One meta-analysis of monetary incentive delay studies suggests that the NAcc and medial caudate may respond more robustly during reward anticipation, but the rostroventral putamen in response to reward outcomes. However, these subcomponents may prove more difficult to dissociate in dynamic studies that involve learning. If different phases of reward-processing recruit distinct VS subcomponents, further enhancements in the spatial and temporal resolution of FMRI may help to test these hypotheses and yield new insights.

\section{AMYGDALA}

The amygdala is a prominent limbic structure that plays a key role in emotional coding of environmental stimuli. It provides contextual information used for adjusting motivational level. The amygdala has an important role in reward processing, in part through the critical interactions between it and VS for stimulus-reward associations (Baxter and Murray, 2002; Cador et al, 1989; Everitt et al, 1989, 1999; Murray, 2007; Ramirez and Savage, 2007). As indicated above, those connections terminate most densely in the NAcc, but extend throughout much of the VS. However, relative to VS activation, amygdalar activation appears less frequently in neuroimaging studies of reward. Although the amygdala has been prominently implicated in fear learning in animal studies (LeDoux, 2000), other animal studies have also implicated the amygdala in reward processing - particularly when previously rewarding stimuli are devalued
(Baxter and Murray, 2002). Metabolic PET studies have reported amygdalar activation in contexts involving potential rewards (particularly related to drug craving), but overall have reported more reliable amygdalar activity in contexts involving potential punishment (see Zald, 2003 for a review).

FMRI studies, too, have reported amygdalar activation in the context of potential reward (McClure et al, 2004b). Controlling for arousal, however, direct comparison of amygdalar responses to rewarding $v s$ punishing stimuli often reveals no significant differences, leading researchers to infer that the amygdalar signal in FMRI responds more to stimulus arousal than value (ie, positive or negative) (Anderson et al, 2003; Small et al, 2003). This inference is consistent with the commonly observed rapid habituation of amygdalar activation to emotional stimuli in FMRI studies (Breiter et al, 1996), which stands in contrast to the relative constancy of VS activation to reward cues over time. For example, one study illustrated temporal dynamics of amygdalar signal by tracking both amygdalar and NAcc activation over time as people learned to associate cues with rewarding or punishing odors (Gottfried et al, 2003). Although amygdalar responses to the rewarding cue decreased over time, NAcc responses to the rewarding cue increased over time. Despite suggesting a less direct function than the VS in reward processing, in line with animal findings, FMRI studies have documented that amygdalar activation decreases with reward devaluation (Gottfried et al, 2003).

\section{VENTRAL PALLIDUM (Figure 8)}

The VP is an important component of the reward circuit in that cells in this forebrain region respond specifically during the learning and performance of reward-incentive behaviors. It, like the VS, is an area of focus in the study of addictive behaviors (Mitrovic and Napier, 2002; Smith and Berridge, 2007; Tindell et al, 2006). The term VP was first used to describe, in rats, the forebrain region below the anterior commissure, extending into the anterior perforated space that contained pallidal-like cells. This area was included as part of the pallidum based both on histological criteria and the fact that it received its input from the VS (Heimer, 1978). Pallidal neurons have a distinct morphology, which is nicely outlined using immunohistochemistry for the peptides, enkephalin, and substance P. Staining for these peptides was particularly useful for determining the boundaries of the VP (DiFiglia et al, 1982; Fox et al, 1974; Haber and Nauta, 1983; Haber and Watson, 1985; Mai et al, 1986; Reiner et al, 1999). Based on these staining patterns and its input from the VS, the VP is now considered to encompass not only the subcommissural regions, but also the rostral pole of the external segment and the medial rostral internal segment of the globus pallidus. The VP also reaches rostrally to invade the rostral and ventral portions of the VS. In the human brain, the VP 


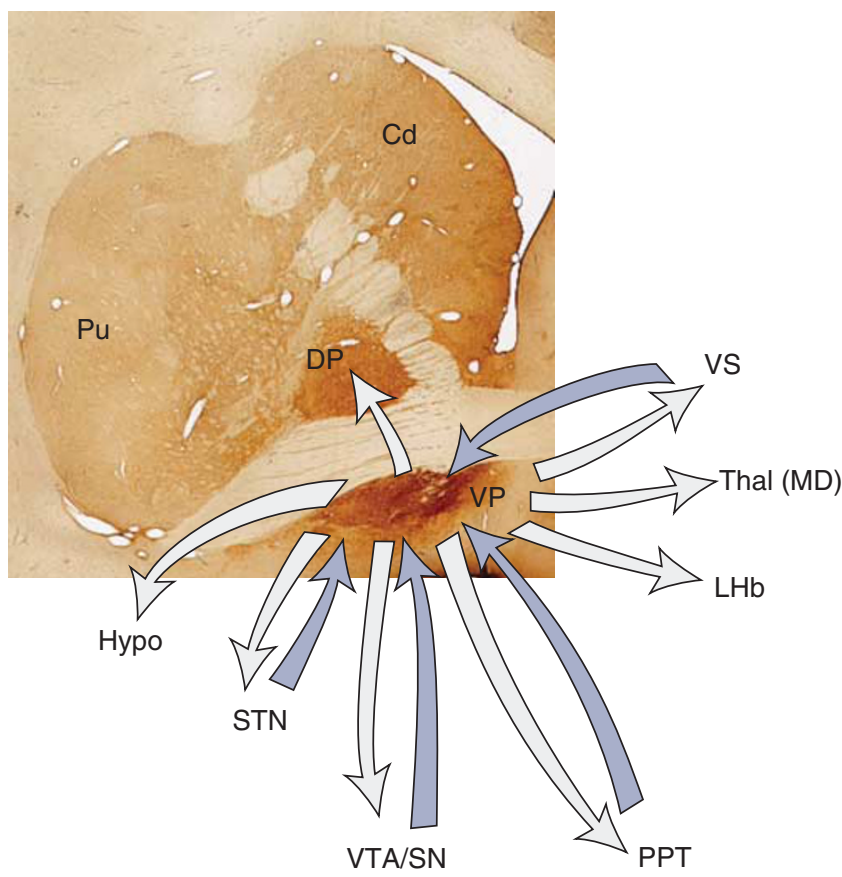

Figure 8. Schematic illustrating the connections of the VP. Blue arrows =inputs; gray arrows=outputs; $\mathrm{DP}=$ dorsal pallidum; hy$\mathrm{po}=$ hypothalamus; $\mathrm{LHb}=$ lateral habenula; $\mathrm{MD}=$ medio-dorsal nucleus of the thalamus; PPT=pedunculopontine nucleus; $S N=$ substantia nigra; STN = subthalamic nucleus; Thal $=$ thalamus; $V P=$ ventral pallidum; VTA = ventral tegmental area.

extends far into the anterior perforated space, where the structure is broken up into an interconnected lacework of pallidal areas, interdigitating with islands of Calleja (Heimer and Alheid, 1991). The identification of the VS and VP simplified the structural analysis of ventral forebrain. It demonstrated that a large part of the area referred to as 'substantia innominata' is actually an extension of the reward-related striatopallidal complex (Alheid and Heimer, 1988). In addition to receiving VS input, the VP also receives a glutamatergic input from the subthalamic nucleus (STN) and a dopaminergic input from the midbrain (Klitenick et al, 1992; Turner et al, 2001) (Figure 8).

The VP projects topographically to the STN and adjacent hypothalamus (Figure 8). Axons also continue to the midbrain, terminating medially in the substantia nigra pars compacta $(\mathrm{SNc})$, pars reticulata $(\mathrm{SNr})$, and VTA (Haber et al, 1993, 1990b; Parent et al, 1997). These fibers are less topographically organized compared with those that project to the STN. Here, terminals from the VP interface with those from other basal ganglia circuits (Bevan et al, 1996). Fibers continue caudally to innervate the pedunculopontine nucleus. Cells of the VP that receive substance $\mathrm{P}$ striatal input project to the MD thalamic nucleus (Haber et al, 1993; Parent et al, 1999; Sidibe et al, 1997). The VP also projects to both the internal and external segments of the dorsal pallidum. This is a unique projection, in that the dorsal pallidum does not seem to project ventrally. Parts of the VP (along with the dorsal pallidum) project to the LHb, a structure now considered to be part of the reward circuit (Matsumoto and Hikosaka, 2007; Morissette and Boye, 2008; Ullsperger and von Cramon, 2003); Haber et al, 1993 \#554; Parent, 1981 \#12010 (see section below for a discussion of the habenular nucleus). Finally, part of the VP (as with the external segment of the pallidum) also projects to the striatum (Spooren et al, 1996). This pallidostriatal pathway is extensive and more widespread than reciprocal striatopallidal projection. In summary, the complexity of the VP circuitry coupled with its central position in the reward circuit indicates that this structure is likely to be activated during imaging studies. Many neuroimaging studies that document ventral striatal activation also document overlapping ventral pallidal activation. However, these methods lack sufficient spatial resolution to distinguish the VP from the VS. Therefore, these imaging studies are not reviewed separately here.

\section{MIDBRAIN DOPAMINE NEURONS}

\section{Organization of the Dopamine Neurons}

The central function of the dopamine neurons in the reward circuit is now well established (Schultz, 2002; Wise, 2002). Behavioral and pharmacological studies of dopamine pathways have lead to the association of the mesolimbic pathway with reward processing and nigro-striatal pathway with motor activity. However, more recently both of these projections have been associated with reward (Schultz, 2002). We first review the organization of the midbrain dopamine cells, and then turn to a discussion of their projections and associated functions.

Dopamine cell groups. The midbrain dopamine neurons are classically divided into the SNc, the VTA, and the retrorubral cell groups (Hokfelt et al, 1984). In human and nonhuman primates, the $\mathrm{SNc}$ is further divided into three groups: a dorsal group ( $\alpha$ or pars dorsalis), a densocellular region (the $\beta$ group), and the cell columns (the $\gamma$ group) (Francois et al, 1985; Haber et al, 1995b; Halliday and Tork, 1986; Olszewski and Baxter, 1982; Poirier et al, 1983). The dorsal group is composed of loosely arranged cells, extending dorsolaterally circumventing the ventral and lateral superior cerebellar peduncle and the red nucleus. These neurons, which form a continuous band with the VTA, are oriented horizontally and do not extend into the ventral parts of the SNc or into the SNr. Calbindin, a calcium binding protein, is an important phenotypic marker for both the VTA and the dorsal SNc and illustrates the continuity of these two cell groups (Haber et al, 1995b; Lavoie and Parent, 1991; McRitchie and Halliday, 1995). In contrast, the dendritic arbors of the ventral cell groups are oriented ventrally and extend deep into the SNr. The interweaving of dopamine cells and dendrites in the $\mathrm{SNr}$ is particularly prominent in human and nonhuman primates. These ventral cell groups are calbindin negative, but have 
high expression levels for DAT and for the D2 receptor mRNAs (Ciliax et al, 1995; Counihan and Penney, 1998; Haber et al, 1995b; Hersch et al, 1997). Based on these and other characteristics, the midbrain dopamine neurons are divided into two tiers: a dorsal tier (the dorsal SNc and the contiguous VTA) that is calbindin-positive, has relatively low expression levels for DAT and the D2R mRNAs, and is selectively spared from neurodegeneration; and a ventral tier (the densocellular region and the cell columns) that is calbindin-negative, has relatively high levels of neuromelanin and expression of DAT and the D2 receptor mRNA, and is selectively vulnerable to neurodegeneration (Burns et al, 1983; German et al, 1992; Haber et al, 1995b; Parent and Lavoie, 1993) (Figure 9a). Connection of the dopamine neurons have been extensively studied for several species. Below, we briefly review those pathways, focusing on primate studies.

Afferent projections. Input to the midbrain dopamine neurons comes primarily from the striatum, from both the external segment of the globus pallidus and the VP, and from the brainstem (Figure 9b). In addition, there are
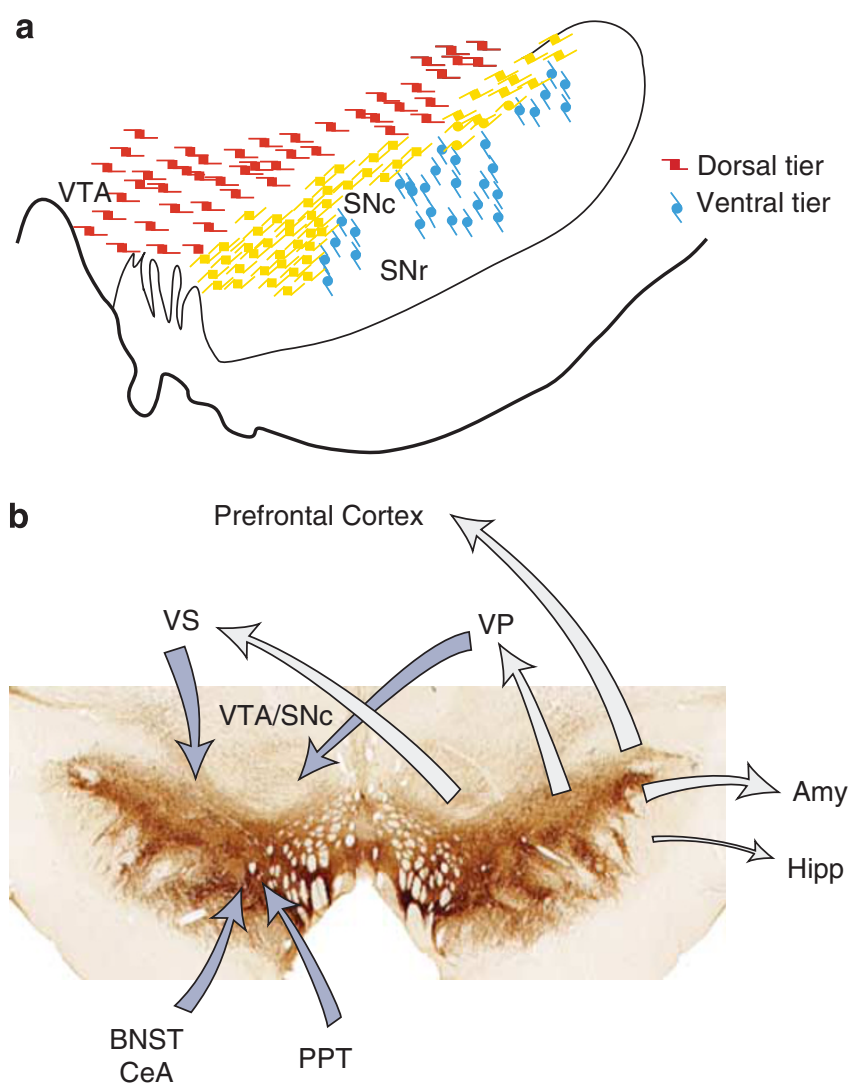

Figure 9. Schematic illustrating the organization (a) and connections (b) of the midbrain dopamine cells. Red cells = connections with VS regions; yellow cells = connections with dorsal caudate nucleus; blue cells $=$ connections with motor control striatal areas. BNST = bed nucleus stria terminalis; $\mathrm{CeA}=$ central amygdala nucleus; $\mathrm{Amy}=$ amygdala; Hipp = hippocampus; PPT = Pedunculopontine nucleus; SNc = substantia nigra, pars compacta; $\mathrm{VP}=$ ventral pallidum; $\mathrm{VTA}=$ ventral tegmental area. projections to the dorsal tier from the bed nucleus of the stria terminalis, from the sublenticular substantia innominata, and the extended amygdala (the bed nucleus of the stria terminalis and the central amygdala nucleus). The striatonigral projection is a massive projection to the midbrain dopamine cells and terminates in both the VTA/ $\mathrm{SNc}$ and the SNr. There is medial/lateral topography and inverse ventral/dorsal topography to these projections, such that the dorsal striatonigral inputs are concentrated in the ventral midbrain and the ventral striatal projects to the dorsal midbrain. In particular, the ventral striatum terminates in the dorsal tier, the dorsal part of the ventral tier, and in the medial and dorsal SNr (Haber et al, 2000; Hedreen and DeLong, 1991; Lynd-Balta and Haber, 1994a; Szabo, 1979). Projections from the pallidum follow a similar inverse dorsal/ventral organization as the striatonigral projection. Thus, the VP projects dorsally, primarily to the dorsal tier and dorsal SNc (Haber et al, 1993; Parent et al, 1984).

Descending projections from the extended amgydala also terminate in a wide medio-lateral region, but are limited primarily to the dorsal tier cells (Fudge and Haber, 2000; Fudge and Haber, 2001). The pedunculopontine nucleus sends a major glutamatergic input to the dopaminergic cells bodies (Lavoie and Parent, 1994a) and there is a serotonergic innervation from the dorsal raphe nucleus (Corvaja et al, 1993; Gervais and Rouillard, 2000; Mori et al, 1987). Other brainstem inputs to the dopamine neurons include those from the superior colliculus (May et al, 2009). This input raises the interesting possibility that dopamine cells receive a direct sensory projection. The collicular input has been suggested to be responsible for the short latency, burst-firing activity of the dopamine cells in response to a salient or rewarding stimuli (Dommett et al, 2005). Finally, in primates, there is a small and relatively limited projection from the PFC to the midbrain DA neurons in primates. These fibers terminate in both the VTA and SNc (Frankle et al, 2006).

Efferent projections. The midbrain dopamine neurons project massively to the striatum (Hedreen and DeLong, 1991; Lynd-Balta and Haber, 1994b; Selemon and GoldmanRakic, 1990; Szabo, 1979) (Figure 9b). As with the descending striatonigral pathway, there is a medio-lateral and an inverse dorsoventral topography arrangement to the projection. Thus, the ventral SNc neurons project to the dorsal striatum and the dorsal tier dopamine neurons project to the VS. The shell region of the NAcc receives the most limited midbrain input, primarily derived from the medial VTA (Lynd-Balta and Haber, 1994c). The rest of the VS receives input from the dorsal tier and from the medial and dorsal part SNc. In contrast to the VS, the central striatal area (the region innervated by the $\mathrm{dPFC}$ ) receives input from a wide region of the SNc. The dorsolateral (motor-related) striatum receives the largest midbrain projection from cells throughout the ventral tier and the VS receives the most limited dopamine cell input. Thus, in addition to an inverse topography, there is also a 
differential ratio of dopamine projections to the different striatal areas (Haber et al, 2000). These characteristics are important when considering how information flows between different functional striatal regions through their projection to the midbrain (see below).

In addition to striatal input, the dorsal tier cells also project widely throughout the primate cortex. Tyrosine hydroxylase-positive fibers are found not only in granular frontal cortex, but also in agranular frontal regions, parietal cortex, temporal cortex, and albeit sparsely, in occipital cortex (Gaspar et al, 1992; Lidow et al, 1991). The dopamine cells that project to these functionally diverse cortical regions are intermingled with each other. Moreover, individual neurons often send collateral axons to different cortical regions. Thus, the nigrocortical projection is a more diffuse system compared with the more topographically organized nigro-striatal system. Dopamine fibers are located in superficial layers in primate cortex, including a prominent projection throughout layer I and are also found in the deep layers in specific cortical areas (Goldman-Rakic et al, 1999; Lewis, 1992; Williams and Goldman-Rakic, 1993). Finally, dopamine neurons, in particular the dorsal tier, project to the wide range of midline structures, including the hypothalamus, periaqueductal gray, the bed nucleus of the stria terminalis, and to the amygdala and hippocampus.

Striato-nigro-striatal network. The idea that VS can influence the dorsal striatum through the midbrain dopamine cells originated in rodent studies, which demonstrated (both at the light and electron microscopy levels) projections from the NAcc to the dorsal striatum, through the SN (Nauta et al, 1978b; Somogyi et al, 1981). Through this pathway, therefore, limbic regions could impact on the motor regions of the basal ganglia (Nauta and Domesick, 1978a). The concept of transferring information through different functional regions of the striatum was later expanded, taking into account the functional diversity of the striatum in monkeys (Haber et al, 2000). In monkeys, projections from the striatum to the midbrain and from the midbrain to the striatum each create a loose topographic organization. The VTA and medial SN are associated with limbic regions, and the central and ventrolateral SN are associated with the associative and motor striatal regions, respectively. However, as indicated above, each functional region differs in their proportional projections. The VS receives a limited midbrain input, but projects to a large region. In contrast, the dorsolateral striatum receives a wide input, but projects to a limited region. In other words, the VS influences a wide range of dopamine neurons, but is itself influenced by a relatively limited group of dopamine cells. On the other hand, the dorsolateral striatum influences a limited midbrain region, but is affected by a relatively large midbrain region.

Thus, while the main efferent projection from the VS to the midbrain is to the dorsal tier, this projection field extends beyond the tight VS/dorsal tier/VS circuit. Indeed, the VS also terminates in the ventral tier, in a position to influence more dorsal striatal regions, particularly those that receive input from associative cortical regions (dPFC). This part of the ventral tier is reciprocally connected to the central (or associative) striatum. The central striatum also projects to a more ventral region than it receives input from. This region, in turn, projects to the dorsolateral (or motor) striatum. Taken together, the interface between different striatal regions through the midbrain DA cells is organized in an ascending spiral interconnecting different functional regions of the striatum and creating a feed forward organization from reward-related regions of the striatum to cognitive and motor areas (Figure 10).

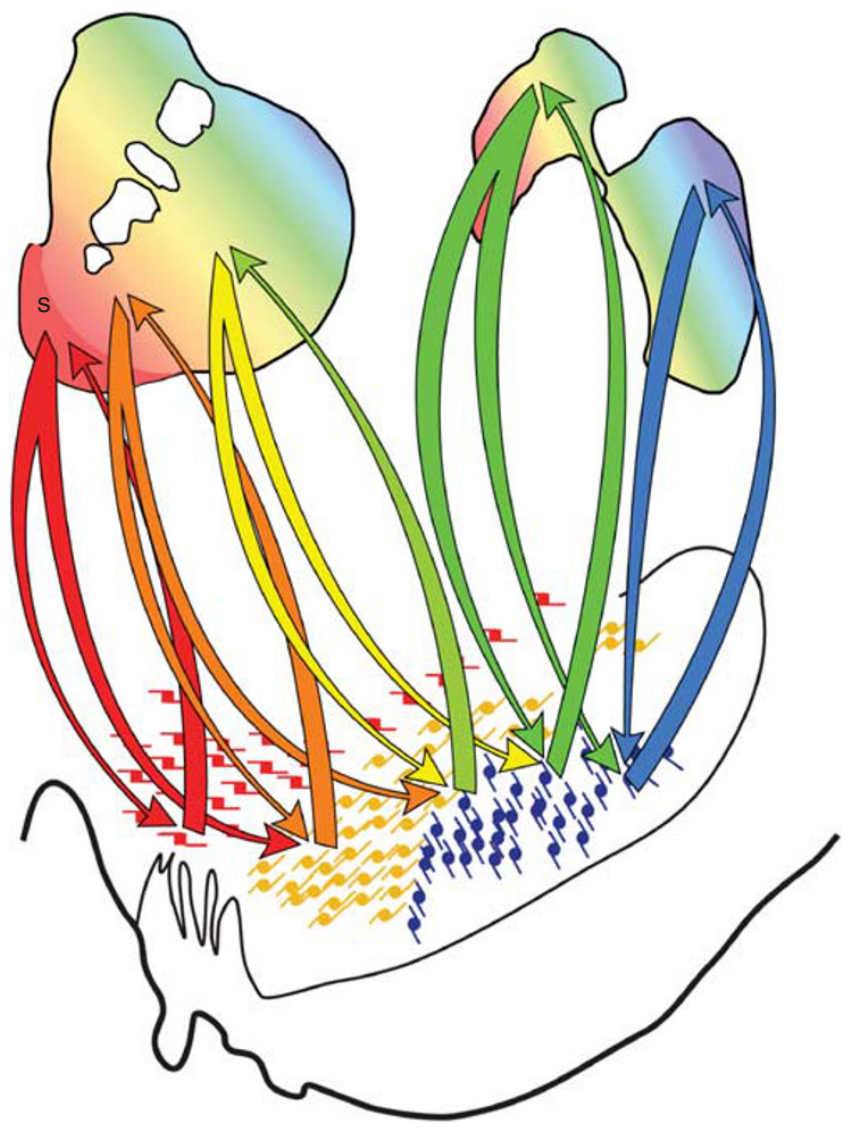

Figure 10. Schematic illustrating the complex connections between the striatum and SN. The arrows illustrate how the VS can influence the dorsal striatum through the midbrain dopamine cells. Colors indicate functional regions of the striatum based on cortical inputs. Midbrain projections from the shell target both the VTA and ventromedial SNc. Projections from the VTA to the shell form a 'closed,' reciprocal loop, but also project more laterally to impact on dopamine cells that project to the rest of the VS, forming the first part of a feed forward loop (or spiral). The spiral continues through the striato-nigro-striatal projections through which the VS impacts cognitive and motor striatal areas through the midbrain dopamine cells; red = inputs from the vmPFC; orange $=$ inputs from the OFC and dACC; yellow=inputs from the dPFC; green and blue $=$ inputs from motor control areas. 
Although the short latency burst-firing activity of dopamine that signals immediate reinforcement is likely to be triggered from brainstem nuclei (Dommett et al, 2005), the cortico-striato-midbrain pathway is in the position to influence dopamine cells to distinguish rewards and modify responses to incoming salient stimuli over time. This pathway is further reinforced through the nigro-striatal pathway, placing the striato-nigro-striatal pathway in a pivotal position for transferring information from the VS to the dorsal striatum during learning and habit formation. Indeed, cells in the dorsal striatum are progressively recruited during different types of learning from simple motor tasks to drug self-administration (Everitt and Robbins, 2005; Lehericy et al, 2005; Pasupathy and Miller, 2005; Porrino et al, 2004; Volkow et al, 2006). Moreover, when the striato-nigro-striatal circuit is interrupted, information transfer from classical to instrumental learning does not take place (Belin and Everitt, 2008).

\section{Reward Processing in the Human Midbrain}

Event-related FMRI currently offers sufficient spatial resolution to allow investigators to visualize changes in the activity of specific midbrain nuclei (Duzel et al, 2009). After electrophysiological evidence that reward prediction and prediction errors alter the firing of midbrain dopamine neurons in monkeys (Schultz, 2002), a growing body of FMRI research has begun to examine midbrain activity during reward processing in human beings. Less neuroimaging work research has focused on midbrain regions than on striatal and prefrontal regions, however, because the midbrain suffers from artifacts related to inhomogeneity (because of its nearness to tissue boundaries), endogenous motion (because of its proximity to the carotid artery), and partial voluming (because of its small size). In addition, while the VTA is difficult to visualize on structural FMRI scans, the SN is not (because of its dark appearance), but investigators can localize the VTA with respect to the SN and other landmarks (including the midline of the brain).

FMRI researchers have reported increased midbrain activation during anticipation of pleasant tastes (D'Ardenne et al, 2008; O'Doherty et al, 2002), anticipation of monetary gains (Knutson et al, 2005), and during exposure to visual stimuli that evoke romantic love (Aron et al, 2005). Interestingly, in neither the juice nor monetary reward studies did midbrain activation appreciably decrease when anticipated rewards failed to occur (consistent with a reward prediction, but not necessarily a prediction error signal). In addition, midbrain increases in activation have been reported in response to reward-predicting cues (Adcock et al, 2006; Wittmann et al, 2005), and this activation, in concert with medial temporal lobe activation, predicts subsequent enhancements in memory for associated stimuli. In summary, FMRI research suggests that midbrain regions near dorsal tier dopamine neurons, including the VTA, show increased activation in response to stimuli that predict reward. The responsiveness of these regions to other incentive features (eg, punishment, arousal) has received less characterization (Bunzeck and Duzel, 2006).

\section{COMPLETING THE CORTICO-BASAL GANGLIA REWARD CIRCUIT}

In addition to the PFC, VS, VP, and amygdala, other key components of the circuit include the thalamus, the LHb, the raphe nuclei, and the pedunculopontine tegmental nuclei. Each of these structures has complex connectivities with multiple brain regions and their direct associations with the cortico-basal ganglia reward system have been discussed. However, below, we add a few additional important points with respect to their role in the reward circuitry.

\section{Thalamus}

The medial MD nucleus projects to the frontal cortex, and is the final link in the reward circuit. (Haber et al, 1993; Ray and Price, 1993). These connections, however, are bidirectional (Erickson and Lewis, 2004; McFarland and Haber, 2002; Zikopoulos and Barbas, 2007). Moreover, while cortico-thalamic projections of the specific thalamic relay nuclei follow a general rule of reciprocity, the cortical projections to these thalamic nuclei are more extensive than their projections back to cortex (as seen in other thalamocortical systems) (Darian-Smith et al, 1999; McFarland and Haber, 2002; Sherman and Guillery, 1996). Importantly, in addition to the reciprocal connection, there is a nonreciprocal cortico-thalamic component. Thus, while the MD nucleus completes the reward circuit back to cortex, there is a nonreciprocal cortical input to the MD nucleus that is derived from functionally distinct frontal cortical areas. For example, the central MD has not only a reciprocal projections with the OFC, but also a nonreciprocal input from vmPFC. Similarly, more lateral MD areas are not only reciprocally connected to the $\mathrm{APFC}$, but also have a nonreciprocal input from the OFC (McFarland and Haber, 2002). Therefore, similar to the striato-nigro-striatal projection system, the thalamic relay nuclei from the basal ganglia also seem to integrate information flow from reward and higher cortical 'association' areas of the prefrontal cortex. A recent DTI study indicates that integration between these cortical areas in the thalamus is also likely to exist in humans (Draganski et al, 2008).

Both PET and FMRI findings suggest that primary and secondary rewards ( $v s$ nonrewards) can increase thalamic activation (Aharon et al, 2001; Anderson et al, 2003; Blood and Zatorre, 2001; Knutson et al, 2000; Martin-Solch et al, 2001; Rogers et al, 1999; Rolls et al, 2003; Small et al, 2001; Thut et al, 1997). Moreover, a meta-analysis of over 20 event-related FMRI studies using monetary incentive delay tasks indicated that anticipation of reward $v s$ anticipation of punishment did not clearly elicit differential dorsomedial thalamic activation. On the other hand, anticipation of 
reward did clearly elicit more dorsomedial thalamic activation than did reward outcomes (Knutson and Greer, 2008). Together, these findings are consistent with the notion that dorsomedial thalamic activation reflects general arousal to a greater extent than value (ie, either rewarding or punishing).

\section{The Lateral Habenula, Pedunculopontine Tegmental Nucleus, and the Raphe Serotonergic Systems}

Recent studies have emphasized the potential importance of the LHb in regulating the dopamine reward signal (Morissette and Boye, 2008). Experiments show that stimulation of the LHb nuclei in primates results in a negative reward-related signal in SNc. (Matsumoto and Hikosaka, 2007). LHb cells are inhibited by a rewardpredicting stimulus, but fire following a nonreward signal. This stimulation of the LHb directly, or following a nonreward signal inhibits dopamine cells (Ji and Shepard, 2007; Matsumoto and Hikosaka, 2007). An event-related FMRI study featuring adequate spatial and temporal resolution to visualize habenular activity indicated that negative but not positive feedback can activate the habenular complex, consistent with findings from primate electrophysiology (Ullsperger and von Cramon, 2003). Interestingly, few fibers from the LHb directly reach the $\mathrm{SNc}$ in the primates, indicating an indirect regulation of the dopamine signal. There are several possible routes by which the LHb might influence midbrain dopamine firing. In addition to an input from the globus pallidus and VP, other connections include the basal forebrain, preoptic area of hypothalamus, interpeduncular nucleus, pedunculopontine nucleus, raphe nucleus, superior colliculus, pretectal area, central gray, VTA, and reticular formation (Araki et al, 1988; Haber et al, 1993; Herkenham and Nauta, 1977; Parent et al, 1981).

The pedunculopontine tegmental nucleus is connected to multiple basal ganglia structures and provides one of the strongest excitatory inputs to the midbrain dopamine cells (Blaha et al, 1996; Lavoie and Parent, 1994b). Moreover, the cells in this brainstem area receive input from the LHb. Anatomical and physiological studies, coupled with the central function of dopamine for reward prediction error, led to studies that support the hypothesis that PPT may have a function in this reward signal (Kobayashi and Okada, 2007). The brainstem serotonergic system may also play a role in reinforcement behaviors by encoding expected and received rewards (Nakamura et al, 2008). This reward signal could arise from a number of brain regions, but perhaps the strongest candidates include inputs derived from the OFC and vmPFC, the amygdala, the SN, and the LHb (Peyron et al, 1998).

\section{SUMMARY AND CONCLUSIONS}

The reward circuit comprises several cortical and subcortical regions forming a complex network that mediates different aspects of incentive-based learning, leading to adaptive behaviors. To develop an appropriate behavioral response to external environmental stimuli, information about motivation and reward needs to be combined with a strategy and an action plan for obtaining goals. For example, to win at a card game, desire is not sufficient. One has to understand the rules of the game, remember the cards played, and so forth, before executing the play. In addition, there is a complex interaction between the desire to put cards in play and the inhibition of impulse to play them too early. Thus, action plans developed toward obtaining a goal require a combination of reward processing, cognitive planning, and motor control.

Reward, therefore, does not work in isolation, but its pathways interface with circuits that mediate cognitive function to affect motor planning. The pathways and connections reviewed in this chapter clearly show that there are dual cortico-basal ganglia systems permitting both parallel and integrative processing (Figure 11). Thus, within each of the cortico-basal ganglia structures, there are convergence zones that can link the reward pathway with those associated with cognitive function. Through these interactive networks, information about reward can be channeled through cognitive circuits to influence motor
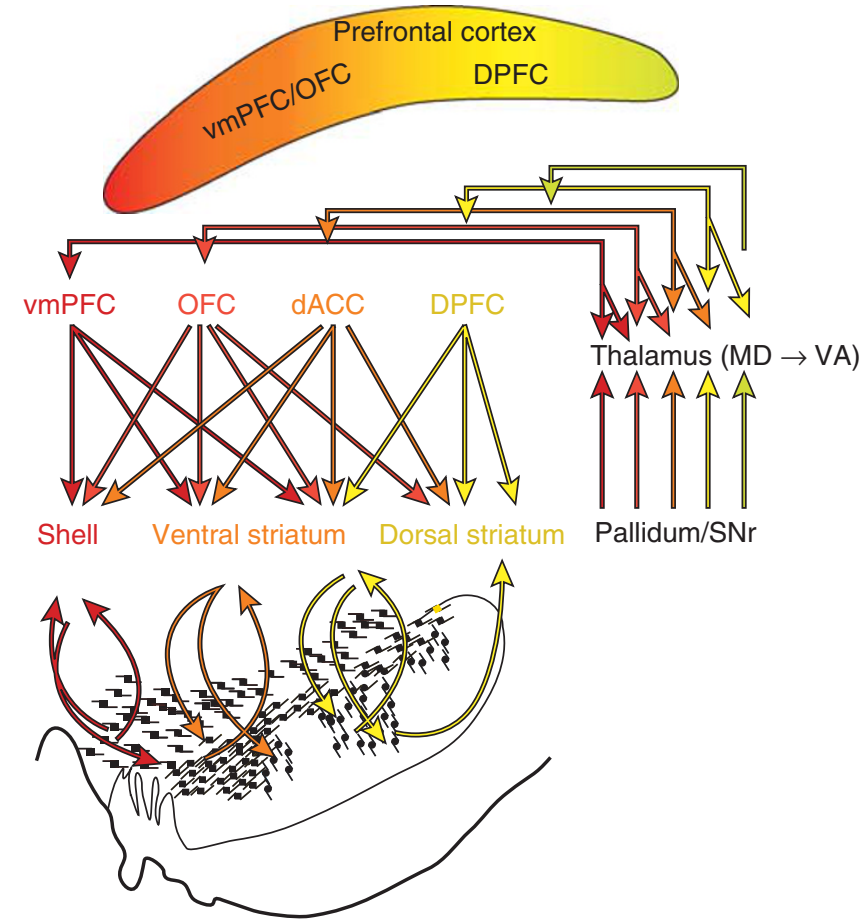

Figure 11. Three networks of integration through cortico-basal ganglia pathways. (1) Fibers from different prefrontal areas converge within subregions of the striatum. (2) Through the organization of striato-nigrostriatal (SNS) projections, the VS can influence the dorsal striatum. (3) The nonreciprocal cortico-thalamic projection carries information from reward-related regions, through cognitive, and motor controls. $\mathrm{dACC}=$ dorsal anterior cingulate cortex; $\mathrm{dPFC}=$ dorsal prefrontal cortex; $\mathrm{OFC}=$ orbital frontal cortex; $\mathrm{vmPFC}=$ ventral medial prefrontal cortex . Red $=$ vmPFC pathways; dark orange $=$ OFC pathways; light orange $=$ $\mathrm{dACC}$ pathways; yellow $=\mathrm{dPFC}$ pathways; green=output to motor control areas. 
control circuits. DTI studies support the idea that interactive networks exist also in the human brain (Draganski et al, 2008). Moreover, fMRI studies provide evidence for functional interactions. For example, while reward anticipation tends to co-activate NAcc and midbrain, reward outcomes subsequently recruit the medial caudate and putamen, followed by the dorsal caudate, including the supplementary motor area. The idea that this recruitment is likely to involve the dopamine pathways through the striato-nigro-striatal spiral is supported by animal behavioral studies (Belin and Everitt, 2008; Porrino et al, 2004). Alternatively, several striatal areas may be coactivated, as in the case for anticipation of reward, by a convergence of different cortico-striatal projections. For example, as indicated above, reward outcomes increased vmPFC and putamen activation, areas that do not appear to have a direct connection. However, within the striatum, the vmPFC projections do converge with those from the OFC in parts of the rostral putamen. Thus, an understanding from animal studies of where these networks interface results in better interpretations of neuroimaging findings in which seemingly unconnected structures can be activated simultaneously. As we learn more about the complexities of circuits, we can hypothesize how other brain regions may be co-activated. Moreover, we are able to better predict where co-activation should occur. This chapter brings together a unique monkey to human translational review that emphasizes the importance of drawing on anatomical constructs developed from primate anatomy to interpret and extend findings from human imaging studies.

The circuitry reviewed in this chapter implies that information flows from ventral to dorsolateral cortico-basal ganglia circuits. Thus, sequentially over time, this suggests a mechanism through which activity occurs across rewardprocessing episodes during the course of learning (Tanaka et al, 2004). Sequential activation also occurs within a single reward-processing episode (eg, from anticipation to outcome). Consistent with this notion, gain prediction error in a typical cued response task occurs first in the $\mathrm{mPFC}$ and NAcc, and subsequently appears in the dorsomedial caudate and putamen parts of the VS seconds later (see Figure 7). The ability to visualize neural activity related to expected value raises the exciting possibility of going beyond correlating brain activation with behavior. It may be possible to use activation to predict behavior. For example, evidence suggests that anticipatory activation in the NAcc and in the mPFC can independently predict approach, whereas anticipatory activation in the connected insular cortex can predict avoidance in financial risk taking, gambling, and purchasing scenarios.

\section{FUTURE DIRECTIONS}

Linking anatomical studies in animals and human imaging is a powerful way to gain insight into brain regions associated with different aspects of reward processing and cognition that lead to appropriate choices. As imaging techniques are refined, we will be able to use results from those studies to explore in depth the underpinnings of coactivation or temporal activation of structures that appear unrelated. One important outcome from these linkages is the validation of imaging results based on what is anatomically well established. As such, neuroimaging has now demonstrated human functional results that map increasingly close to primate anatomy. For example, the adoption of event-related FMRI has generated a proliferation of new results that highlight anticipatory activation in related cortical and striatal regions. Moreover, in the case of neural correlates of expected value, these patterns of activation mapped more closely onto the connected mPFC, VS, and VTA implied by anatomical studies than did earlier functional results. An emerging set of DTI tools for visualizing connectivity in humans promises to further bridge the gap between primate structure and human function (Cohen et al, 2009b; Draganski et al, 2008; Lehericy et al, 2004).

\section{DISCLOSURE}

Dr Haber has received honoraria fees from Lilly and consultation fees from Medtronic. Dr Knutson has no conflicts of interest to declare.

\section{REFERENCES}

Abler B, Walter H, Erk S, Kammerer P, Spitzer M (2006). Prediction error as a linear function of reward probability is coded in the human nucleus accumbens. Neuroimage 31: 790-795.

Adcock RA, Thangavel A, Whitfield-Gabrieli S, Knutson B, Gabrieli JDE (2006). Reward-motivated learning: mesolimbic activation precedes memory formation. Neuron 50: 507-517.

Aharon I, Etcoff N, Ariely D, Chabris CF, O'Connor E, Breiter HC (2001). Beautiful faces have variable reward value: $\mathrm{fMRI}$ and behavioral evidence. Neuron 32: 537-551.

Akert K, Hartmann-von Monakow K (1980). Relationships of precentral, premotor and prefrontal cortex to the mediodorsal and intralaminar nuclei of the monkey thalamus. Acta Neurobiol Exp 40: 7-25.

Alexander GE, Crutcher MD, DeLong MR (1990). Basal ganglia-thalamocortical circuits: parallel substrates for motor, oculomotor, 'prefrontal' and 'limbic' functions. Prog Brain Res 85: 119-146.

Alheid GF, Heimer L (1988). New perspectives in basal forebrain organization of special relevance for neuropsychiatric disorders: the striatopallidal, amygdaloid, and corticopetal components of substantia innominata. Neuroscience 27: 1-39.

Anderson AK, Christoff K, Stappen I, Panitz D, Ghahremani DG, Glover GH et al (2003). Dissociated neural representations of intensity and valence in human olfaction. Nat Neurosci 6: 196-202.

Araki M, McGeer PL, Kimura H (1988). The efferent projections of the rat lateral habenular nucleus revealed by the PHA-L anterograde tracing method. Brain Res 441: 319-330.

Aron A, Fisher H, Mashek DJ, Strong G, Li H, Brown LL (2005). Reward, motivation, and emotion systems associated with early-stage intense romantic love. J Neurophysiol 94: 327-337.

Averbeck BB, Seo M (2008). The statistical neuroanatomy of frontal networks in the macaque. PLoS Comput Biol 4: e1000050.

Ballard K, Knutson B (2009). Dissociable neural representations of future reward magnitude and delay during temporal discounting. Neuroimage 45: 143-150.

Barbas $H$ (1992). Architecture and cortical connections of the prefrontal cortex in the rhesus monkey. In: Chauvel P, Delgado-Escueta AV (eds). Advances in Neurology. Raven Press, Ltd: New York. pp 91-115.

Baxter MG, Murray EA (2002). The amygdala and reward. Nat Rev Neurosci 3: 563-573. 
Bayer SA (1985). Neurogenesis in the olfactory tubercle and islands of calleja in the rat. Int J Devl Neurosci 3: 135-147.

Beach TG, Tago H, McGeer EG (1987). Light microscopic evidence for a substance P-containing innervation of the human nucleus basalis of Meynert. Brain Res 408: 251-257.

Bechara A, Damasio AR, Damasio H, Anderson SW (1994). Insensitivity to future consequences following damage to human prefrontal cortex. Cognition 50: 7-15.

Belin D, Everitt BJ (2008). Cocaine seeking habits depend upon dopaminedependent serial connectivity linking the ventral with the dorsal striatum. Neuron 57: 432-441.

Berendse HW, Groenewegen HJ (1990). The organization of the thalamostriatal projections in the rat, with special emphasis on the ventral striatum. J Comp Neurol 299: 187-228.

Berns GS, McClure SM, Pagnoni G, Montague PR (2001). Predictability modulates human brain response to reward. J Neurosci 21: 2793-2798.

Bevan MD, Clarke NP, Bolam JP (1997). Synaptic integration of functionally diverse pallidal information in the entopeduncular nucleus and subthalamic nucleus in the rat. J Neurosci 17: 308-324.

Bevan MD, Smith AD, Bolam JP (1996). The substantia nigra as a site of synaptic integration of functionally diverse information arising from the ventral pallidum and the globus pallidus in the rat. Neuroscience 75 : 5-12.

Blaha CD, Allen LF, Das S, Inglis WL, Latimer MP, Vincent SR. et al (1996). Modulation of dopamine efflux in the nucleus accumbens after cholinergic stimulation of the ventral tegmental area in intact, pedunculopontine tegmental nucleus-lesioned, and laterodorsal tegmental nucleus-lesioned rats. J Neurosci 16: 714-722.

Blair K, Marsh AA, Morton J, Vythilingam M, Jones M, Mondillo K et al (2006). Choosing the lesser of two evils, the better of two goods: specifying the roles of ventromedial prefrontal cortex and dorsal anterior cingulate in object choice. J Neurosci 26: 11379-11386.

Blood AJ, Zatorre RJ (2001). Intensely pleasurable responses to music correlate with activity in brain regions implicated in reward and emotion. Proc Natl Acad Sci USA 98: 11818-11823.

Boileau I, Assaad JM, Pihl RO, Benkelfat C, Leyton M, Diksic M et al (2003). Alcohol promotes dopamine release in the human nucleus accumbens. Synapse $\mathbf{4 9}$ 226-231

Botvinick M, Nystrom LE, Fissell K, Carter CS, Cohen JD (1999a). Conflict monitoring vs selection-for-action in anterior cingulate cortex. Nature 402 179-181.

Botvinick M, Nystrom LE, Fissell K, Carter CS, Cohen JD (1999b). Conflict monitoring vs selection-for-action in anterior cingulate cortex. Nature 402 179-181.

Botvinick MM, Huffstetler S, McGuire JT (2009). Effort discounting in human nucleus accumbens. Cogn Affect Behav Neurosci 9: 16-27.

Bowman EM, Aigner TG, Richmond BJ (1996). Neural signals in the monkey ventral striatum related to motivation for juice and cocaine rewards. J Neurophysiol 75 : 1061-1073.

Bray S, O'Doherty J (2007). Neural coding of reward-prediction error signals during classical conditioning with attractive faces. J Neurophysiol 97: 3036-3045.

Breiter HC, Aharon I, Kahneman D, Dale A, Shizgal P (2001). Functional imaging of neural responses to expectancy and experience of monetary gains and losses. Neuron 30: 619-639.

Breiter HC, Etcoff NL, Whalen PJ, Kennedy WA, Rauch SL, Buckner RL et al (1996). Response and habituation of the human amygdala during visual processing of facial expression. Neuron 17: 875-887.

Breiter HC, Gollub RL, Weisskoff RM, Kennedy DN, Makris N, Berke JD et al (1997). Acute effects of cocaine on human brain activity and emotion. Neuron 19: 591-611.

Brodmann K (1909). Vergleichende Lokalisationslehre der Grosshirnrinde. J.A. Barth: Leipzig.

Brown LL, Smith DM, Goldbloom LM (1998). Organizing principles of cortical integration in the rat neostriatum: corticostriate map of the body surface is an ordered lattice of curved laminae and radial points. J Comp Neurol 392: 468-488.

Bruguier A, Preuschoff K, Quartz S, Bossaerts P (2008). Investigating signal integration with canonical correlation analysis of $\mathrm{fMRI}$ brain activation data. Neuroimage 41: 35-44.

Buckner RL (1998). Event-related FMRI and the hemodynamic response. Hum Brain Mapp 6: 373-377.

Bunzeck N, Duzel E (2006). Absolute coding of stimulus novelty in the human substantia nigra/VTA. Neuron 51: 369-379.

Burns RS, Chiueh CC, Markey SP, Ebert MH, Jacobowitz DM, Kopin IJ (1983). A primate model of parkinsonism: selective destruction of dopaminergic neurons in the pars compacta of the substantia nigra by $\mathrm{N}$-methyl-4-phenyl-1,2,3,6tetrahydropyridine. Proc Natl Acad Sci USA 80: 4546-4550.
Cador M, Robbins TW, Everitt BJ (1989). Involvement of the amygdala in stimulusreward associations: interaction with the ventral striatum. Neuroscience 30(No. 1): 77-86.

Carlezon WA, Wise RA (1996). Rewarding actions of phencyclidine and related drugs in nucleus accumbens shell and frontal cortex. J Neurosci 16: 3112-3122.

Carmichael ST, Price JL (1994). Architectonic subdivision of the orbital and medial prefrontal cortex in the macaque monkey. J Comp Neurol 346: 366-402.

Carr GD, White NM (1983). Conditioned place preference from intra-accumbens but not intra-caudate amphetamine injections. Life Sci 33: 2551-2557.

Chang HT, Penny GR, Kitai ST (1987). Enkephalinergic-cholinergic interaction in the rat globus pallidus: a pre-embedding double-labeling immunocytochemistry study. Brain Res 426: 197-203.

Charpier S, Mahon S, Deniau JM (1999). In vivo induction of striatal long-term potentiation by low-frequency stimulation of the cerebral cortex. Neuroscience 91: 1209-1222.

Chikama M, McFarland N, Amaral DG, Haber SN (1997). Insular cortical projections to functional regions of the striatum correlate with cortical cytoarchitectonic organization in the primate. J Neurosci 17: 9686-9705.

Chronister RB, Sikes RW, Trow TW, DeFrance JF (1981). The organization of the nucleus accumbens. In: Chronister RB, DeFrance JF (eds). The Neurobiology of the Nucleus Accumbens. Haer Institute: Brunswick, ME, pp 97-146.

Ciliax BJ, Heilman C, Demchyschyn LL, Pristupa ZB, Ince E, Hersch SM et al (1995). The dopamine transporter: immunochemical characterization and localization in brain. J Neurosci 15: 1714-1723.

Cohen MX, Axmacher N, Lenartz D, Elger CE, Sturm V, Schlaepfer TE (2009a). Neuroelectric signatures of reward learning and decision-making in the human nucleus accumbens. Neuropsychopharmacology 34: 1649-1658.

Cohen MX, Schoene-Bake JC, Elger CE, Weber B (2009b). Connectivity-based segregation of the human striatum predicts personality characteristics. Nat Neurosci 12: 32-34.

Cooper JC, Knutson B (2008). Valence and salience contribute to nucleus accumbens activation. Neuroimage 39: 538-547.

Corvaja N, Doucet G, Bolam JP (1993). Ultrastructure and synaptic targets of the raphe-nigral projection in the rat. Neuroscience 55: 417-427.

Counihan TJ, Penney Jr JB (1998). Regional dopamine transporter gene expression in the substantia nigra from control and Parkinson's disease brains. J Neurol Neurosurg Psychiatry 65: 164-169.

Cox SM, Benkelfat C, Dagher A, Delaney JS, Durand F, McKenzie SA. et al (2009). Striatal dopamine responses to intranasal cocaine self-administration in humans. Biol Psychiatry 65: 846-850.

Cromwell HC, Schultz W (2003). Effects of expectations for different reward magnitudes on neuronal activity in primate striatum. J Neurophysiol 89 2823-2838.

Croxson PL, Walton ME, O'Reilly JX, Behrens TEJ, Rushworth MFS (2009). Effort based cost-benefit valuation and the human brain. J Neurosci 29: 4531-4541.

D'Ardenne K, McClure SM, Nystrom LE, Cohen JD (2008). BOLD responses reflecting dopaminergic signals in the human ventral tegmental area. Science 319: 1264-1267.

Darian-Smith C, Tan A, Edwards S (1999). Comparing thalamocortical and corticothalamic microstructure and spatial reciprocity in the macaque ventral posterolateral nucleus (VPLC) and medial pulvinar. J Comp Neurol 410: 211-234

Daw ND, O'Doherty JP, Dayan P, Seymour B, Dolan RJ (2006). Cortical substrates for exploratory decisions in humans. Nature 441: 876-879.

De Martino B, Kumaran D, Holt B, Dolan RJ (2009). The neurobiology of referencedependent value computation. J Neurosci 29: 3833-3842.

Delgado MR, Locke HM, Stenger VA, Fiez JA (2003). Dorsal striatum responses to reward and punishment: effects of valence and magnitude manipulations. Cogn Affect Behav Neurosci 3: 27-38.

Delgado MR, Miller MM, Inati S, Phelps EA (2005). An fMRI study of reward-related probability learning. Neuroimage 24: 862-873.

Delgado MR, Nystrom LE, Fissell C, Noll DC, Fiez JA (2000). Tracking the hemodynamic responses to reward and punishment in the striatum. J Neurophysiol 84: 3072-3077.

DiFiglia M, Aronin N, Martin JB (1982). Light and electron microscopic localization of immunoreactive leu-enkephalin in the monkey basal ganglia. J Neurosci 2(No. 3): 303-320.

Dommett E, Coizet V, Blaha CD, Martindale J, Lefebvre V, Walton N et al (2005). How visual stimuli activate dopaminergic neurons at short latency. Science 307 : 1476-1479.

Draganski B, Kherif F, Kloppel S, Cook PA, Alexander DC, Parker GJ. et al (2008). Evidence for segregated and integrative connectivity patterns in the human basal ganglia. J Neurosci 28: 7143-7152. 
Dreher JC, Kohn P, Berman KF (2006). Neural coding of distinct statistical properties of reward information in humans. Cereb Cortex 16: 561-573.

Drevets WC, Gautier C, Price JC, Kupfer DJ, Kinahan PE, Grace AA. et al (2001). Amphetamine-induced dopamine release in human ventral striatum correlates with euphoria. Biol Psychiatry 49: 81-96.

Duzel E, Bunzeck N, Guitart-Masip M, Wittmann B, Schott BH, Tobler PN (2009). Functional imaging of the human dopaminergic midbrain. Trends Neurosci 32: 321-328.

Elliott R, Dolan RJ, Frith CD (2000a). Dissociable functions in the medial and lateral orbitofrontal cortex: evidence from human neuroimaging studies. Cereb Cortex 10: 308-317.

Elliott R, Friston KJ, Dolan RJ (2000b). Dissociable neural responses in human reward systems. J Neurosci 20: 6159-6165.

Elliott R, Frith CD, Dolan RJ (1997). Differential neural response to positive and negative feedback in planning and guessing tasks. Neuropsychologia 35: 1395-1404.

Erickson SL, Lewis DA (2004). Cortical connections of the lateral mediodorsal thalamus in cynomolgus monkeys. J Comp Neurol 473: 107-127.

Everitt BJ, Cador M, Robbins TW (1989). Interactions between the amygdala and ventral striatum in stimulus-reward associations: studies using a second-order schedule of sexual reinforcement. Neuroscience 30(No. 1): 63-75.

Everitt BJ, Parkinson JA, Olmstead MC, Arroyo M, Robledo P, Robbins TW (1999). Associative processes in addiction and reward. The role of amygdala-ventral striatal subsystems. Ann N Y Acad Sci 877: 412-438.

Everitt BJ, Robbins TW (2005). Neural systems of reinforcement for drug addiction: from actions to habits to compulsion. Nat Neurosci 8: 1481-1489.

Ferry AT, Ongur D, An X, Price JL (2000). Prefrontal cortical projections to the striatum in macaque monkeys: evidence for an organization related to prefrontal networks. J Comp Neurol 425: 447-470.

Flaherty AW, Graybiel AM (1993). Two input systems for body representations in the primate striatal matrix: experimental evidence in the squirrel monkey. $J$ Neurosci 13: $1120-1137$.

Fletcher PC, Henson RN (2001). Frontal lobes and human memory: insights from functional neuroimaging. Brain 124(Pt 5): 849-881.

Fox CH, Andrade HN, Du Qui IJ, Rafols JA (1974). The primate globus pallidus. A Golgi and electron microscope study. J R Hirnforschung 15: 75-93.

Francois C, Percheron G, Yelnik J, Heyner S (1985). A histological atlas of the macaque (macaca mulatta) substantia nigra in ventricular coordinates. Brain Res Bull 14: 349-367.

Frankle WG, Laruelle M, Haber SN (2006). Prefrontal cortical projections to the midbrain in primates: evidence for a sparse connection. Neuropsychopharmacology 31: 1627-1636.

Friedman DP, Aggleton JP, Saunders RC (2002). Comparison of hippocampal, amygdala, and perirhinal projections to the nucleus accumbens: combined anterograde and retrograde tracing study in the Macaque brain. J Comp Neurol 450: 345-365.

Fudge JL, Haber SN (2000). The central nucleus of the amygdala projection to dopamine subpopulations in primates. Neuroscience 97: 479-494.

Fudge JL, Haber SN (2001). Bed nucleus of the stria terminalis and extended amygdala inputs to dopamine subpopulations in primates. Neuroscience 104: 807-827.

Fudge JL, Kunishio K, Walsh C, Richard D, Haber SN (2002). Amygdaloid projections to ventromedial striatal subterritories in the primate. Neuroscience 110: $257-275$.

Fuster JM (2001). The prefrontal cortex - an update: time is of the essence. Neuron 30: 319-333.

Gaspar P, Stepneiwska I, Kaas JH (1992). Topography and collateralization of the dopaminergic projections to motor and lateral prefrontal cortex in owl monkeys. $\checkmark$ Comp Neurol 325: 1-21.

German DC, Manaye KF, Sonsalla PK, Brooks BA (1992). Midbrain dopaminergic cell loss in Parkinson's disease and MPTP- induced parkinsonism: sparing of calbindin-D28k-containing cells. Ann N Y Acad Sci 648: 42-62.

Gervais J, Rouillard C (2000). Dorsal raphe stimulation differentially modulates dopaminergic neurons in the ventral tegmental area and substantia nigra. Synapse 35: 281-291.

Giménez-Amaya JM, McFarland NR, de las Heras S, Haber SN (1995). Organization of thalamic projections to the ventral striatum in the primate. J Comp Neurol 354: 127-149.

Glascher J, Hampton AN, O'Doherty JP (2009). Determining a role for ventromedial prefrontal cortex in encoding action-based value signals during reward-related decision making. Cereb Cortex 19: 483-495.

Goldman-Rakic PS, Bergson C, Krimer LS, Lidow MS, Williams SM, Williams GV (1999). The primate mesocortical dopamine system. In: Bloom FE, Bjorklund A, Hokfelt T (eds). Handbook of Chemical Neuroanatomy, Vol 15 Elsevier Science: Amsterdam.
Gottfried JA, O'Doherty J, Dolan RJ (2002). Appetitive and aversive olfactory learning in humans studied using event-related functional magnetic resonance imaging. J Neurosci 22: 10829-10837.

Gottfried JA, O'Doherty J, Dolan RJ (2003). Encoding predictive reward value in human amygdala and orbitofrontal cortex. Science 301: 1104-1107.

Haber SN (1987). Anatomical relationship between the basal ganglia and the basal nucleus of Maynert in human and monkey forebrain. Proc Natl Acad Sci USA 84: 1408-1412.

Haber SN, Fudge JL, McFarland NR (2000). Striatonigrostriatal pathways in primates form an ascending spiral from the shell to the dorsolateral striatum. J Neurosci 20: 2369-2382.

Haber SN, Groenewegen HJ, Grove EA, Nauta WJH (1985). Efferent connections of the ventral pallidum. Evidence of a dual striatopallidofugal pathway. J Comp Neurol 235: 322-335

Haber SN, Kim KS, Mailly P, Calzavara R (2006). Reward-related cortical inputs define a large striatal region in primates that interface with associative cortical inputs, providing a substrate for incentive-based learning. J Neurosci 26: 8368-8376.

Haber SN, Kunishio K, Mizobuchi M, Lynd-Balta E (1995a). The orbital and medial prefrontal circuit through the primate basal ganglia. J Neurosci 15(7 Pt 1): 4851-4867.

Haber SN, Lynd E, Klein C, Groenewegen HJ (1990a). Topographic organization of the ventral striatal efferent projections in the rhesus monkey: an anterograde tracing study. J Comp Neurol 293: 282-298.

Haber SN, Lynd-Balta E, Mitchell SJ (1993). The organization of the descending ventral pallidal projections in the monkey. J Comp Neurol 329: 111-129.

Haber SN, McFarland NR (1999). The concept of the ventral striatum in nonhuman primates. Ann N Y Acad Sci 877: 33-48.

Haber SN, Nauta WJH (1983). Ramifications of the globus pallidus in the rat as indicated by patterns of immunohistochemistry. Neuroscience 9: 245-260.

Haber SN, Ryoo H, Cox C, Lu W (1995b). Subsets of midbrain dopaminergic neurons in monkeys are distinguished by different levels of mRNA for the dopamine transporter: comparison with the mRNA for the D2 receptor, tyrosine hydroxylase and calbindin immunoreactivity. J Comp Neurol 362: 400-410.

Haber SN, Watson SJ (1985). The comparative distribution of enkephalin, dynorphin and substance $P$ in the human globus pallidus and basal forebrain. Neuroscience 14: 1011-1024.

Haber SN, Wolfe DP, Groenewegen HJ (1990b). The relationship between ventral striatal efferent fibers and the distribution of peptide-positive woolly fibers in the forebrain of the rhesus monkey. Neuroscience 39: 323-338.

Halliday GM, Tork I (1986). Comparative anatomy of the ventromedial mesencephalic tegmentum in the rat, cat, monkey and human. J Comp Neurol 252: 423-445.

Harrington KA, Augood SJ, Kingsbury AE, Foster OJ, Emson PC (1996). Dopamine transporter (DAT) and synaptic vesicle amine transporter (VMAT2) gene expression in the substantia nigra of control and Parkinson's disease. Brain Res Mol Brain Res 36: 157-162.

Hedreen JC, DeLong MR (1991). Organization of striatopallidal, striatonigal, and nigrostriatal projections in the Macaque. J Comp Neurol 304: 569-595.

Heimer $L$ (1978). The olfactory cortex and the ventral striatum. In: Livingston KE, Hornykiewicz O (eds). Limbic Mechanisms. Plenum Press: New York, pp 95-187.

Heimer L, Alheid GF (1991). Piecing together the puzzle of basal forebrain anatomy. In: Napier TC, Kalivas PW, Hanin I (eds). The Basal Forebrain: Anatomy to Function. Plenum publishing: New York, New York.

Heimer L, De Olmos JS, Alheid GF, Person J, Sakamoto N, Shinoda K et al (1999). The human basal forebrain. Part II. In: Bloom FE, Bjorkland A, Hokfelt T (eds). Hanbook of Chemical Neuroanatomy Vol 15 Elsevier: Amsterdam.

Heimer L, Switzer RD, Van Hoesen GW (1982). Ventral striatum and ventral pallidum. Components of the motor system? Trends Neurosci 5: 83-87.

Herkenham M, Nauta WJH (1977). Afferent connections of the habenular nuclei in the rat. A horseradish peroxidase study, with a note on the fiber-of-passage problem. J Comp Neurol 173: 123-146.

Hersch SM, Yi H, Heilman CJ, Edwards RH, Levey Al (1997). Subcellular localization and molecular topology of the dopamine transporter in the striatum and substantia nigra. J Comp Neurol 388: 211-227.

Hikosaka O, Bromberg-Martin E, Hong S, Matsumoto M (2008). New insights on the subcortical representation of reward. Curr Opin Neurobiol 18: 203-208.

Hokfelt T, Martensson R, Bjorklund A, Kleinau S, Goldstein M (1984). Distributional maps of tyrosine-hydroxylase immunoreactive neurons in the rat brain. In: Bjorklund A, Hokfelt T (eds). Handbook of Chemical Neuroanatomy, Vol. II: Classical Neurotransmitters in the CNS, Part I Elsevier: Amsterdam. pp 277-379.

Hsu M, Krajbich I, Zhao C, Camerer CF (2009). Neural response to reward anticipation under risk is nonlinear in probabilities. J Neurosci 29: 2231-2237.

Ikemoto K, Satoh K, Maeda T, Fibiger HC (1995). Neurochemical heterogeneity of the primate nucleus accumbens. Exp Brain Res 104: 177-190. 
Ito R, Robbins TW, Everitt BJ (2004). Differential control over cocaine-seeking behavior by nucleus accumbens core and shell. Nat Neurosci 7: 389-397.

Jensen J, Mclntosh AR, Crawley AP, Mikulis DJ, Remington G, Kapur S (2003). Direct activation of the ventral striatum in anticipation of aversive stimuli. Neuron 40: 1251-1257.

Ji H, Shepard PD (2007). Lateral habenula stimulation inhibits rat midbrain dopamine neurons through a GABA(A) receptor-mediated mechanism. J Neurosci 27: 6923-6930.

Joel D, Weiner I (1994). The organization of the basal ganglia-thalamocortical circuits: open interconnected rather than closed segregated. Neuroscience 63: 363-379.

Kable JW, Glimcher PW (2007). The neural correlates of subjective value during intertemporal choice. Nat Neurosci 10: 1625-1633.

Kalivas PW, Volkow N, Seamans J (2005). Unmanageable motivation in addiction: a pathology in prefrontal-accumbens glutamate transmission. Neuron 45: $647-650$

Kasanetz F, Riquelme LA, Della-Maggiore V, O'Donnell P, Murer MG (2008). Functional integration across a gradient of corticostriatal channels controls UP state transitions in the dorsal striatum. Proc Natl Acad Sci USA 105: 8124-8129.

Kelley AE, Berridge KC (2002). The neuroscience of natural rewards: relevance to addictive drugs. J Neurosci 22: 3306-3311.

Kennerley SW, Wallis JD (2009). Reward-dependent modulation of working memory in lateral prefrontal cortex. J Neurosci 29: 3259-3270.

Kim H, Shimojo S, O'Doherty JP (2006). Is avoiding an aversive outcome rewarding? Neural substrates of avoidance learning in the human brain. PLOS Biol 4: e233.

Klitenick MA, Deutch AY, Churchill L, Kalivas PW (1992). Topography and functional role of dopaminergic projections from the ventral mesencephalic tegmentum to the ventral pallidum. Neuroscience 50: 371-386.

Knutson B, Adams CM, Fong GW, Hommer D (2001a). Anticipation of increasing monetary reward selectively recruits nucleus accumbens. I Neurosci 21: RC159.

Knutson B, Bhanji JP, Cooney RE, Atlas LY, Gotlib IH (2008). Neural responses to monetary incentives in major depression. Biol Psychiatry 63: 686-692.

Knutson B, Fong GW, Adams CM, Varner JL, Hommer D (2001b). Dissociation of reward anticipation and outcome with event-related fMRI. Neuroreport 12 3683-3687.

Knutson B, Fong GW, Bennett SM, Adams CM, Hommer D (2003). A region of mesial prefrontal cortex tracks monetarily rewarding outcomes: characterization with rapid event-related fMRI. Neuroimage 18: 263-272.

Knutson B, Greer SM (2008). Anticipatory affect: neural correlates and consequences for choice. Philos Trans $R$ Soc $B$ 363: 3771-3786.

Knutson B, Rick S, Wimmer GE, Prelec D, Loewenstein G (2007). Neural predictors of purchases. Neuron 53: 147-156.

Knutson B, Taylor J, Kaufman M, Peterson R, Glover G (2005). Distributed neural representation of expected value. J Neurosci 25: 4806-4812.

Knutson B, Westdorp A, Kaiser E, Hommer D (2000). FMRI visualization of brain activity during a monetary incentive delay task. Neuroimage 12: 20-27.

Kobayashi Y, Okada K (2007). Reward prediction error computation in the pedunculopontine tegmental nucleus neurons. Ann N Y Acad Sci 1104: 310-323.

Koepp MJ, Gunn RN, Lawrence AD, Cunningham VJ, Dagher A, Jones T. et al (1998). Evidence for striatal dopamine release during a video game. Nature 393: 266-268.

Kolomiets BP, Deniau JM, Mailly P, Menetrey A, Glowinski J, Thierry AM (2001). Segregation and convergence of information flow through the cortico-subthalamic pathways. J Neurosci 21: 5764-5772.

Kringelbach ML, Rolls ET (2004). The functional neuroanatomy of the human orbitofrontal cortex: evidence from neuroimaging and neuropsychology. Prog Neurobiol 72: 341-372.

Kuhnen CM, Knutson B (2005). The neural basis of financial risk taking. Neuron 47: 763-770.

Kunig G, Leenders KL, Martin-Solch C, Missimer J, Magyar S, Schultz W (2000). Reduced reward processing in the brains of Parkinsonian patients. Neuroreport 11: 3681-3687.

Lavoie B, Parent A (1991). Dopaminergic neurons expressing calbindin in normal and parkinsonian monkeys. Neuroreport 2(No. 10): 601-604.

Lavoie B, Parent A (1994a). Pedunculopontine nucleus in the squirrel monkey: cholinergic and glutamatergic projections to the substantia nigra. J Comp Neurol 344: 232-241.

Lavoie B, Parent A (1994b). Pedunculopontine nucleus in the squirrel monkey: projections to the basal ganglia as revealed by anterograde tract-tracing methods. J Comp Neurol 344: 210-231.

LeDoux JE (2000). Emotion circuits in the brain. Annu Rev Neurosci 23: 155-184.
Lehericy S, Benali H, Van de Moortele PF, Pelegrini-Issac M, Waechter T, Ugurbil K. et al (2005). Distinct basal ganglia territories are engaged in early and advanced motor sequence learning. Proc Natl Acad Sci USA 102: 12566-12571.

Lehericy S, Ducros M, Van de Moortele PF, Francois C, Thivard L, Poupon C et al (2004). Diffusion tensor fiber tracking shows distinct corticostriatal circuits in humans. Ann Neurol 55: 522-529.

Lewis DA (1992). The catecholaminergic innervation of primate prefrontal cortex. J Neural Transm Supp/ 36: 179-200.

Leyton M, Boileau I, Benkelfat C, Diksic M, Baker G, Dagher A (2002). Amphetamine-induced increases in extracellular dopamine, drug wanting, and novelty seeking: A PET/[11C]raclopride study in healthy men. Neuropsychopharmacology 27: 1027-1034.

Lidow MS, Goldman-Rakic PS, Gallager DW, Rakic P (1991). Distribution of dopaminergic receptors in the primate cerebral cortex: quantitative autoradiographic analysis using $[3 \mathrm{H}]$ raclopride, $[3 \mathrm{H}]$ spiperone and $[3 \mathrm{H}] \mathrm{sch} 23390$. Neuroscience 40 (No. 3) 657-671.

Lohrenz T, McCabe K, Camerer CF, Montague PR (2007). Neural signature of fictive learning signals in a sequential investment task. Proc Natl Acad Sci 104: 9493-9498.

Lynd-Balta E, Haber SN (1994a). Primate striatonigral projections: a comparison of the sensorimotor-related striatum and the ventral striatum. J Comp Neurol 345 562-578.

Lynd-Balta E, Haber SN (1994b). The organization of midbrain projections to the striatum in the primate: sensorimotor-related striatum vs ventral striatum. Neuroscience 59: 625-640.

Lynd-Balta E, Haber SN (1994c). The organization of midbrain projections to the ventral striatum in the primate. Neuroscience 59: 609-623.

Lyons D, Friedman DP, Nader MA, Porrino LJ (1996). Cocaine alters cerebral metabolism within the ventral striatum and limbic cortex of monkeys. $J$ Neurosci 16: $1230-1238$.

MacDonald AWr, Cohen JD, Stenger VA, Carter CS (2000). Dissociating the role of the dorsolateral prefrontal and anterior cingulate cortex in cognitive control. Science 288: 1835-1839.

Mai JK, Stephens PH, Hopf A, Cuello AC (1986). Substance P in the human brain. Neuroscience 17(No. 3): 709-739.

Mallet N, Le Moine C, Charpier S, Gonon F (2005). Feedforward inhibition of projection neurons by fast-spiking GABA interneurons in the rat striatum in vivo. J Neurosci 25: 3857-3869.

Martin LJ, Blackstone CD, Levey Al, Huganir RL, Price DL (1993). AMPA glutamate receptor subunits are differentially distributed in rat brain. Neuroscience $\mathbf{5 3}$ : 327-338.

Martinez D, Slifstein M, Broft A, Mawlawi O, Hwang DR, Huang Y et al (2003). Imaging human mesolimbic dopamine transmission with positron emission tomography. Part II: amphetamine-induced dopamine release in the functional subdivisions of the striatum. J Cereb Blood Flow Metab 23: 285-300.

Martinez-Murillo R, Blasco I, Alvarez FJ, Villalba R, Solano ML, Montero-Caballero $\mathrm{Ml}$ et al (1988). Distribution of enkephalin-immunoreactive nerve fibers and terminals in the region of the nucleus basalis magnocellularis of the rat: a light and electron microscopic study. J Neurocytol 17: 361-376.

Martin-Solch C, Magyar S, Kunig G, Missimer J, Schultz W, Leenders KL (2001). Changes in brain activation associated with reward processing in smokers and nonsmokers. A positron emission tomography study. Exp Brain Res 139 : 278-286.

Matsumoto M, Hikosaka O (2007). Lateral habenula as a source of negative reward signals in dopamine neurons. Nature 447: 1111-1115.

Mawlawi O, Martinez D, Slifstein M, Broft A, Chatterjee R, Hwang DR. et al (2001). Imaging human mesolimbic dopamine transmission with positron emission tomography: I. Accuracy and precision of $D(2)$ receptor parameter measurements in ventral striatum. I Cereb Blood Flow Metab 21 1034-1057.

May PJ, McHaffie JG, Stanford TR, Jiang H, Costello MG, Coizet V et al (2009). Tectonigral projections in the primate: a pathway for pre-attentive sensory input to midbrain dopaminergic neurons. Eur J Neurosci 29: 575-587.

McClure SM, Berns GS, Montague PR (2003). Temporal prediction errors in a passive learning task activate human striatum. Neuron 38: 339-346.

McClure SM, Ericson KM, Laibson DI, Loewenstein G, Cohen JD (2007). Time discounting for primary rewards. J Neurosci 27: 5796-5804.

McClure SM, Laibson DI, Loewenstein G, Cohen JD (2004a). Separate neural systems value immediate and delayed monetary rewards. Science 306 : 503-507.

McClure SM, York MK, Montague PR (2004b). The neural substrates of reward processing in humans: the modern role of FMRI. Neuroscientist 10: 260-268.

McFarland NR, Haber SN (2001). Organization of thalamostriatal terminals from the ventral motor nuclei in the macaque. J Comp Neurol 429: 321-336. 
McFarland NR, Haber SN (2002). Thalamic relay nuclei of the basal ganglia form both reciprocal and nonreciprocal cortical connections, linking multiple frontal cortical areas. J Neurosci 22: 8117-8132.

McRitchie DA, Halliday GM (1995). Calbindin D28K-containing neurons are restricted to the medial substantia nigra in humans. Neuroscience 65: 87-91.

Mena-Segovia J, Ross HM, Magill PJ, Bolam JP (2005). The Pedunculopontine Nucleus: Towards a Functional Integration with the Basal Ganglia. Springer Science and Business Media: New York, 533-544pp.

Menon V, Levitin DJ (2005). The rewards of music listening: response and physiological connectivity of the mesolimbic system. Neuroimage 28: 175-184.

Meredith GE, Pattiselanno A, Groenewegen HJ, Haber SN (1996). Shell and core in monkey and human nucleus accumbens identified with antibodies to calbindinD28k. J Comp Neurol 365: 628-639.

Meyer G, Gonzalez-Hernandez T, Carrillo-Padilla F, Ferres-Torres R (1989). Aggregations of granule cells in the basal forebrain (islands of Calleja): Golgi and cytoarchitectonic study in different mammals, including man. J Comp Neurol 284: 405-428.

Mitrovic I, Napier TC (2002). Mu and kappa opioid agonists modulate ventral tegmental area input to the ventral pallidum. Eur J Neurosci 15: 257-268.

Mobbs D, Greicius MD, Abdel-Azim E, Menon V, Reiss AL (2003). Humor modulates the mesolimbic reward centers. Neuron 40: 1041-1048.

Mogenson GJ, Jones DL, Yim CY (1980). From motivation to action: functional interface between the limbic system and the motor system. Prog Neurobiol 14: 69-97.

Montague PR, Dayan P, Sejnowski TJ (1996). A framework for mesencephalic dopamine systems based on predictive hebbian learning. J Neurosci 16: 1936-1947.

Mori S, Matsuura T, Takino T, Sano Y (1987). Light and electron microscopic immunohistochemical studies of serotonin nerve fibers in the substantia nigra of the rat, cat and monkey. Anat Embryol 176: 13-18.

Morissette MC, Boye SM (2008). Electrolytic lesions of the habenula attenuate brain stimulation reward. Behav Brain Res 187: 17-26.

Murray EA (2007). The amygdala, reward and emotion. Trends Cogn Sci 11: 489-497

Nakamura K, Matsumoto M, Hikosaka O (2008). Reward-dependent modulation of neuronal activity in the primate dorsal raphe nucleus. J Neurosci 28: 5331-5343.

Nauta HJW (1986). The relationship of the basal ganglia to the limbic system. In: Vinken PJ, Bruyn GW, Klawans JJ (eds). Handbook of Clinical Neurology: Extrapyramidal Disorders Vol 5 Elsevier Science Publishers: Amsterdam. pp 19-31.

Nauta WJ, Mehler WR (1966). Projections of the lentiform nucleus in the monkey. Brain Res 1: 3-42.

Nauta WJH, Domesick VB (1978a). Crossroads of limbic and striatal circuitry: hypothalamic-nigral connections. In: Livingston KE, Hornykiewicz O (eds). Limbic Mechanisms. Plenum Publishing Corp.: New York. pp 75-93.

Nauta WJH, Smith GP, Faull RLM, Domesick VB (1978b). Efferent connections and nigral afferents of the nucleus accumbens septi in the rat. Neuroscience 3 : 385-401.

Nieuwenhuis S, Heslenfeld DJ, von Geusau NJ, Mars RB, Holroyd CB, Yeung N (2005). Activity in human reward-sensitive brain areas is strongly context dependent. Neuroimage 25: 1302-1309.

O'Doherty J, Critchley H, Deichmann R, Dolan RJ (2003a). Dissociating valence of outcome from behavioral control in human orbital and ventral prefrontal cortices. J Neurosci 23: 7931-7939.

O'Doherty J, Dayan P, Schultz J, Deichmann R, Friston K, Dolan RJ (2004). Dissociable roles of ventral and dorsal striatum in instrumental conditioning. Science 304: 452-454

O'Doherty J, Kringelbach ML, Rolls ET, Hornak J, Andrews C (2001). Abstract reward and punishment representations in the human orbitofrontal cortex. Nat Neurosci 4: 95-102.

O'Doherty JP, Dayan P, Friston K, Critchley H, Dolan RJ (2003b). Temporal difference models and reward-related learning in the human brain. Neuron 38: 329-337

O'Doherty JP, Deichmann R, Critchley HD, Dolan RJ (2002). Neural responses during anticipation of a primary taste reward. Neuron 33: 815-826.

Olds J, Milner P (1954). Positive reinforcement produced by electrical stimulation of septal area and other regions of rat brain. J Comp Physiol Psychol 47: 419-427.

Olszewski J, Baxter D (1982). Cytoarchitecture of the Human Brain Stem, 2nd edn. S. Karger: Basel.

Ongur D, Price $\mathrm{JL}$ (2000). The organization of networks within the orbital and medial prefrontal cortex of rats, monkeys and humans. Cereb Cortex 10: 206-219

Oya H, Adolphs R, Kawasaki H, Bechara A, Damasio A, Howard III MA (2005). Electrophysiological correlates of reward prediction error recorded in the human prefrontal cortex. Proc Natl Acad Sci USA 102: 8351-8356.
Padoa-Schioppa C, Assad JA (2006). Neurons in the orbitofrontal cortex encode economic value. Nature 441: 223-226.

Pappata S, Dehaene S, Poline JB, Gregoire MC, Jobert A, Delforge J et al (2002). In vivo detection of striatal dopamine release during reward: a PET study with $[(11) C]$ raclopride and a single dynamic scan approach. Neuroimage 16: 1015-1027.

Parent A, Bouchard C, Smith Y (1984). The striatopallidal and striatonigral projections: two distinct fiber systems in primate. Brain Res 303: 385-390.

Parent A, Gravel S, Boucher R (1981). The origin of forebrain afferents to the habenula in rat, cat and monkey. Brain Res Bull 6: 23-38.

Parent A, Hazrati LN (1995). Functional anatomy of the basal ganglia. I. The corticobasal ganglia-thalamo-cortical loop. Brain Res Rev 20: 91-127.

Parent A, Hazrati L-N, Charara A (1997). The striatopallidal fiber system in primates. In: Obeso JD, MR; Ohye, C, Marsden, CD (eds). The Basal Ganglia and New Surgical Approaches for Parkinson's Disease, Advances in Neurology Vol 74 Lippincott-Raven: Philadelphia. pp 19-29.

Parent A, Lavoie B (1993). The heterogeneity of the mesostriatal dopaminergic system as revealed in normal and Parkinsonian monkeys. Adv Neurol 60: 25-33.

Parent M, Levesque M, Parent A (1999). The pallidofugal projection system in primates: evidence for neurons branching ipsilaterally and contralaterally to the thalamus and brainstem. J Chem Neuroanat 16: 153-165.

Parent M, Parent A (2006). Single-axon tracing study of corticostriatal projections arising from primary motor cortex in primates. J Comp Neurol 496: 202-213.

Parkinson JA, Cardinal RN, Everitt BJ (2000). Limbic cortical-ventral striatal systems underlying appetitive conditioning. Prog Brain Res 126: 263-285.

Passingham RE, Stephan KE, Kotter R (2002). The anatomical basis of functional localization in the cortex. Nat Rev Neurosci 3: 606-616.

Pasupathy A, Miller EK (2005). Different time courses of learning-related activity in the prefrontal cortex and striatum. Nature 433: 873-876.

Paus T (2001). Primate anterior cingulate cortex: where motor control, drive and cognition interface. Nat Rev Neurosci 2: 417-424.

Percheron G, Filion M (1991). Parallel processing in the basal ganglia: up to a point. Trends Neurosci 14: 55-59.

Petrides M, Alivisatos B, Frey S (2002). Differential activation of the human orbital, mid-ventrolateral, and mid-dorsolateral prefrontal cortex during the processing of visual stimuli. Proc Natl Acad Sci USA 99: 5649-5654.

Petrides M, Pandya DN (1994). Comparative architectonic analysis of the human and macaque frontal cortex. In: Boller F, Grafman J (eds). Handbook of Neuropsychology. Elsevier: Amsterdam. pp 17-58.

Peyron C, Petit JM, Rampon C, Jouvet M, Luppi PH (1998). Forebrain afferents to the rat dorsal raphe nucleus demonstrated by retrograde and anterograde tracing methods. Neuroscience 82: 443-468.

Phillips AG, Fibiger HC (1978). The role of dopamine in maintaining intracranial selfstimulation in the ventral tegmentum, nucleus accumbens, and medial prefrontal cortex. Can J Psychol 32: 58-66.

Plassmann H, O'Doherty J, Rangel A (2007). Orbitofrontal cortex encodes willingness to pay in everyday economic transactions. J Neurosci 27: 9984-9988.

Poirier LJ, Giguere M, Marchand R (1983). Comparative morphology of the substantia nigra and ventral tegmental area in the monkey, cat and rat. Brain Res Bull 11: 371-397.

Poldrack RA, Prabhakaran V, Seger CA, Gabrieli JD (1999). Striatal activation during acquisition of a cognitive skill. Neuropsychology 13: 564-574.

Porrino LJ, Lyons D, Smith HR, Daunais JB, Nader MA (2004). Cocaine selfadministration produces a progressive involvement of limbic, association, and sensorimotor striatal domains. J Neurosci 24: 3554-3562.

Preuschoff K, Bossaerts P, Quartz SR (2006). Neural differentiation of expected reward and risk in human subcortical structures. Neuron 51: 381-390.

Ramanathan S, Hanley JJ, Deniau JM, Bolam JP (2002). Synaptic convergence of motor and somatosensory cortical afferents onto GABAergic interneurons in the rat striatum. J Neurosci 22: 8158-8169.

Ramirez DR, Savage LM (2007). Differential involvement of the basolateral amygdala, orbitofrontal cortex, and nucleus accumbens core in the acquisition and use of reward expectancies. Behav Neurosci 121: 896-906.

Ramnani N, Elliott R, Athwal BS, Passingham RE (2004). Prediction error for free monetary reward in the human prefrontal cortex. Neuroimage 23: 777-786.

Ray JP, Price JL (1993). The organization of projections from the mediodorsal nucleus of the thalamus to orbital and medial prefrontal cortex in Macaque monkeys. J Comp Neurol 337: 1-31.

Reiner A, Medina L, Haber SN (1999). The distribution of dynorphinergic terminals in striatal target regions in comparison to the distribution of substance $\mathrm{P}$-containing and enkephalinergic terminals in monkeys and humans. Neuroscience 88 : $775-793$ 
Ridderinkhof KR, Ullsperger M, Crone EA, Nieuwenhuis S (2004). The role of the medial frontal cortex in cognitive control. Science 306: 443-447.

Roesch MR, Olson CR (2004). Neuronal activity related to reward value and motivation in primate frontal cortex. Science 304: 307-310.

Rogers RD, Owen AM, Middleton HC, Williams EJ, Pickard JD, Sahakian BJ et al (1999). Choosing between small, likely rewards and large, unlikely rewards activates inferior and orbital prefrontal cortex. J Neurosci 19: 9029-9038.

Rolls ET (2000). The orbitofrontal cortex and reward. Cereb Cortex 10: 284-294.

Rolls ET, O'Doherty J, Kringelbach ML, Francis S, Bowtell R, McGlone F (2003). Representations of pleasant and painful touch in the human orbitofrontal and cingulate cortices. Cereb Cortex 13: 308-317.

Russchen FT, Bakst I, Amaral DG, Price JL (1985). The amygdalostriatal projections in the monkey. An anterograde tracing study. Brain Res 329: 241-257.

Sato K, Kiyama H, Tohyama M (1993). The differential expression patterns of messenger RNAs encoding non-N-methyl-D-aspartate glutamate receptor subunits (GluR1-4) in the rat brain. Neuroscience 52: 515-539.

Schultz W (2000). Multiple reward signals in the brain. Nat Rev Neurosci 1 199-207.

Schultz W (2002). Getting formal with dopamine and reward. Neuron 36: 241-263.

Schultz W, Apicella P, Scarnati E, Ljungberg T (1992). Neuronal activity in monkey ventral striatum related to the expectation of reward. J Neurosci 12: 4595-4610.

Schultz W, Dayan P, Montague PR (1997). A neural substrate of prediction and reward. [Review] [37 refs]. Science 275: 1593-1599.

Schultz W, Tremblay L, Hollerman JR (2000). Reward processing in primate orbitofrontal cortex and basal ganglia. Cereb Cortex 10: 272-284.

Selemon LD, Goldman-Rakic PS (1985). Longitudinal topography and interdigitation of corticostriatal projections in the rhesus monkey. J Neurosci 5: 776-794.

Selemon LD, Goldman-Rakic PS (1990). Topographic intermingling of striatonigral and striatopallidal neurons in the rhesus monkey. J Comp Neurol 297 359-376.

Sherman SM, Guillery RW (1996). Functional organization of thalamocortical relays. J Neurophysiol 76: 1367-1395.

Sidibe M, Bevan MD, Bolam JP, Smith Y (1997). Efferent connections of the internal globus pallidus in the squirrel monkey: I. Topography and synaptic organization of the pallidothalamic projection. J Comp Neurol 382: 323-347.

Small DM, Gregory MD, Mak YE, Gitelman D, Mesulam MM, Parrish T (2003). Dissociation of neural representation of intensity and affective valuation in human gustation. Neuron 39: 701-711.

Small DM, Zatorre RJ, Dagher A, Evans AC, Jones-Gotman M (2001). Changes in brain activity related to eating chocolate: from pleasure to aversion. Brain 124 1720-1733.

Smith KS, Berridge KC (2007). Opioid limbic circuit for reward: interaction between hedonic hotspots of nucleus accumbens and ventral pallidum. J Neurosci 27: 1594-1605.

Somogyi P, Bolam JP, Totterdell S, Smith AD (1981). Monosynaptic input from the nucleus accumbens-ventral striatum region to retrogradely labelled nigrostriatal neurones. Brain Res 217: 245-263.

Spooren WPJM, Lynd-Balta E, Mitchell S, Haber SN (1996). Ventral pallidostriatal pathway in the monkey: evidence for modulation of basal ganglia circuits. J Comp Neurol 370: 295-312.

Stefani MR, Moghaddam B (2006). Rule learning and reward contingency are associated with dissociable patterns of dopamine activation in the rat prefrontal cortex, nucleus accumbens, and dorsal striatum. I Neurosci 26: 8810-8818.

Szabo J (1979). Strionigral and nigrostriatal connections. Anatomical studies. App/ Neurophysiol 42: 9-12.

Taha SA, Fields HL (2006). Inhibitions of nucleus accumbens neurons encode a gating signal for reward-directed behavior. J Neurosci 26: 217-222.

Takada M, Tokuno H, Nambu A, Inase M (1998). Corticostriatal input zones from the supplementary motor area overlap those from the contra- rather than ipsilateral primary motor cortex. Brain Res 791: 335-340.

Tanaka SC, Doya K, Okada G, Ueda K, Okamoto Y, Yamawaki S (2004). Prediction of immediate and future rewards differentially recruits cortico-basal ganglia loops. Nat Neurosci 7: 887-893.

Thut G, Schultz W, Roelcke U, Nienhusmeier M, Missimer J, Maguire RP et al (1997). Activation of the human brain by monetary reward. Neuroreport 8: 1225-1228.

Tindell AJ, Smith KS, Pecina S, Berridge KC, Aldridge JW (2006). Ventral pallidum firing codes hedonic reward: when a bad taste turns good. J Neurophysiol 96: 2399-2409.

Tobler PN, Christopoulos GI, O’Doherty JP, Dolan RJ, Schultz W (2008). Neuronal distortions of reward probability without choice. J Neurosci 28: 11703-11711.
Tobler PN, O'Doherty JP, Dolan RJ, Schultz W (2007). Reward value coding distinct from risk attitude-related uncertainty coding in human reward systems. J Neurophysiol 97: 1621-1632.

Tremblay L, Schultz W (2000). Reward-related neuronal activity during go-nogo task performance in primate orbitofrontal cortex. J Neurophysiol 83: 1864-1876.

Tricomi E, Delgado MR, McCandliss BD, McClelland JL, Fiez JA (2006). Performance feedback drives caudate activation in a phonological learning task. J Cogn Neurosci 18: 1029-1043.

Turner MS, Lavin A, Grace AA, Napier TC (2001). Regulation of limbic information outflow by the subthalamic nucleus: excitatory amino acid projections to the ventral pallidum. J Neurosci 21: 2820-2832.

Ullsperger M, von Cramon DY (2003). Error monitoring using external feedback: specific roles of the habenular complex, the reward system, and the cingulate motor area revealed by functional magnetic resonance imaging. J Neurosci 23 4308-4314.

Vogt BA, Vogt L, Farber NB, Bush G (2005). Architecture and neurocytology of monkey cingulate gyrus. J Comp Neurol 485: 218-239.

Volkow ND, Wang GJ, Fowler JS, Logan J, Gatley SJ, Wong C et al (1999). Reinforcing effects of psychostimulants in humans are associated with increases in brain dopamine and occupancy of $\mathrm{D}(2)$ receptors. J Pharmacol Exp Ther 291: 409-415.

Volkow ND, Wang GJ, Telang F, Fowler JS, Logan J, Childress AR et al (2006). Cocaine cues and dopamine in dorsal striatum: mechanism of craving in cocaine addiction. J Neurosci 26: 6583-6588.

Walker AE (1940). A cytoarchitectural study of the prefronal area of the macaque monkey. J Comp Neurol 73: 59-86.

Wallis JD, Miller EK (2003). Neuronal activity in primate dorsolateral and orbital prefrontal cortex during performance of a reward preference task. Eur J Neurosci 18: 2069-2081.

Walton ME, Bannerman DM, Alterescu K, Rushworth MF (2003). Functional specialization within medial frontal cortex of the anterior cingulate for evaluating effort-related decisions. J Neurosci 23: 6475-6479.

Watanabe K, Hikosaka O (2005). Immediate changes in anticipatory activity of caudate neurons associated with reversal of position-reward contingency. J Neurophysiol 94: 1879-1887.

Williams SM, Goldman-Rakic PS (1993). Characterization of the dopaminergic innervation of the primate frontal cortex using a dopamine-specific antibody. Cereb Cortex 3: 199-222.

Wise RA (2002). Brain reward circuitry: insights from unsensed incentives. Neuron 36: 229-240.

Wittmann BC, Schott BH, Guderian S, Frey JU, Heinze HJ, Duzel E (2005). Reward-related FMRI activation of dopaminergic midbrain is associated with enhanced hippocampus-dependent long-term memory formation. Neuron 45 459-467.

Yacubian J, Glascher J, Schroeder K, Sommer T, Braus DF, Buchel C (2006). Dissociable systems for gain- and loss-related value predictions and errors of prediction in the human brain. J Neurosci 26: 9530-9537.

Yacubian J, Sommer T, Schroeder K, Glascher J, Braus DF, Buchel C (2007). Subregions of the ventral striatum show preferential coding of reward magnitude and probability. Neuroimage 38: 557-563

Yakovlev PI, Locke S, Koskoff DY, Patton RA (1960). Limbic nuclei of thalamus and connections of limbic cortex. I. Organization of the projections of the anterior group of nuclei and of the midline nuclei of the thalamux to the anterior cingulate gyrus and hippocampal rudiment in the monkey. Arch Neurol 3: 620-641.

Young III WS, Alheid GF, Heimer L (1984). The ventral pallidal projection to the mediodorsal thalamus: a study with fluorescent retrograde tracers and immunohistofluorescence. J Neurosci 4: 1626-1638.

Zaborszky L, Cullinan WE (1992). Projections from the nucleus accumbens to cholinergic neurons of the ventral pallidum: a correlated light and electron microscopic double-immunolabeling study in rat. Brain Res 570: 92-101.

Zahm DS, Heimer L (1993). Specificity in the efferent projections of the nucleus accumbens in the rat: comparison of the rostral pole projection patterns with those of the core and shell. J Comp Neurol 327: 220-232.

Zald DH (2003). The human amygdala and the emotional evaluation of sensory stimuli. Brain Res Rev 41: 88-123.

Zald DH, Boileau I, El-Dearedy W, Gunn R, McGlone F, Dichter GS et al (2004). Dopamine transmission in the human striatum during monetary reward tasks. J Neurosci 24: 4105-4112.

Zheng T, Wilson CJ (2002). Corticostriatal combinatorics: the implications of corticostriatal axonal arborizations. J Neurophysiol 87: 1007-1017.

Zikopoulos B, Barbas H (2007). Parallel driving and modulatory pathways link the prefrontal cortex and thalamus. PLoS One 2: e848. 